\title{
States in the decomposition of verbal predicates
} Evidence from additive operators

\author{
Giorgos Spathas $^{1} \cdot$ Dimitris Michelioudakis ${ }^{2}$
}

Received: 11 October 2019 / Accepted: 16 November 2020 / Published online: 3 December 2020

(C) The Author(s) 2020

\begin{abstract}
This paper proposes a new diagnostic for the detection of stative sub-events in the decomposition of verbal predicates. The diagnostic is based on a certain type of presupposition triggered by additive operators like Greek ke 'also', which we call Stative Presuppositions. It is argued that the generation of such Stative Presuppositions requires the existence of a syntactically accessible constituent that denotes a predicate of states that additive operators can take scope over. We investigate the distribution of Stative Presuppositions and observe that not all verbs that support inferences to a result state give rise to them. Based on this distribution we argue for a non-uniform analysis of result verbs; whereas some verbs require an event-decompositional analysis, others are better captured by scalar- and incrementality-based analyses. We cast our analysis in the framework of Distributed Morphology and propose to explain nonuniformity based on how different types of verbal roots interact with verbal functional material. Moreover, treating roots as the locus of encyclopedic information explains lexical variation in the generation of Stative Presuppositions within sub-classes of result verbs. We strengthen our conclusions by considering and rejecting alternative syntactic and semantic mechanisms for generating Stative Presuppositions. We conclude that the availability of Stative Presuppositions with additive operators is currently the most reliable diagnostic for the detection of syntactically accessible result states in verbal decomposition.
\end{abstract}

Keywords Verbal semantics · Result state Event structure $\cdot$ Inner aspect $\cdot$ Additive operators · Lexical decomposition

G. Spathas

spathas@leibniz-zas.de

1 ZAS Berlin, Berlin, Germany

2 Aristotle University of Thessaloniki, Thessaloniki, Greece 


\section{Introduction}

Theories of verbal predication are devised to predict which aspects of verbal meaning determine grammatically relevant behavior like classification in aspectual classes, observed entailment patterns, interaction with adverbial modification, availability of nominalization and other derivational processes, etc. In order to state the relevant generalizations, all theories rely on some sort of decomposition of verbal meaning. Such decompositions are comprised of three basic ingredients (cf. Kratzer 2015): (i) variables and logical symbols and relations, (ii) a limited set of (relational) operators (e.g., CAUSE, BECOME, COMP, POS, PART-OF, etc.), and (iii) the idiosyncratic contribution of some lexical primitive, related to encyclopedic knowledge. They differ not only in the set of operators they assume and, correspondingly, in the nature of the underlying ontology (i.e., whether they admit events, degrees, vectors, etc. and how these domains are structured), but also with respect to the level at which decomposition applies, the restrictions on the interaction between the operators and the idiosyncratic component, and the way verbal arguments are integrated.

Two broad types of decomposition that are usually deployed in recent theorizing are scalar- and incrementality-based analyses, on the one hand, and eventdecompositional analyses, on the other. ${ }^{1}$ Scalar-based analyses assume an ontology of primitive entities like degrees or vectors, which are organized in scales. The operators of verbal decomposition, then, operate on degrees or different aspects of scales. In incrementality-based analyses the operators define relations between the mereological properties of different elements in a verbal predication. Eventdecompositional analyses, on the other hand, assume that the main event introduced by a verb is linked to different, distinct 'sub-events,' which can even be parts of the main event. The operators define relations between sub-events or between sub-events and the main event. These basic types of verbal decomposition have been formalized and related to each other in many different ways in the literature giving rise to a great variety of theoretical approaches and analytical options. Moreover, a lot of disagreement regards the exact empirical scope of each type of decomposition and the categorization into sub-classes that each one entails.

This paper focuses on verbal predicates which describe events at whose endpoint some specific and identifiable state obtains. In (1a) this is the state of the clothes being dry and in (1b) the state of the car being in a working condition. We call such states 'result states' (cf. 'target states' in Kratzer 2000) and the verbs in (1) 'result verbs.'
a. The clothes dried.
b. Mary fixed the car.
c. The cat entered the room.

\footnotetext{
${ }^{1}$ For incrementality- and scalar-based analyses see Krifka (1989), Hay et al. (1999), Winter (2006), Kennedy and Levin (2008), Wechsler (2005), Piñón (2008), Rappaport Hovav (2008), Landman and Rothstein (2010), Beavers (2013), Goldschmidt and Zwarts (2016) a.m.o. For different versions of eventdecompositional analyses (all building on Dowty 1979), see Grimshaw (1990), Parsons (1990), Pustejovsky (1991), von Stechow (1996), Rappaport Hovav and Levin (1998), Higginbotham (2000), Rothstein (2004), Alexiadou et al. (2015), a.m.o. Many of these analyses adopt aspects of different types of decomposition, see also Ramchand (2008), Kennedy (2012), Beavers (2011a), a.m.o., and Filip (2012, 2020) for overviews.
} 
d. Nakeema climbed the ladder.

e. Carl knitted a sweater.

f. Billy gave a present to the child.

We make a positive argument for the availability of event-decompositional analyses for at least a subset of such predicates by identifying a phenomenon whose analysis, we argue, requires the existence of stative sub-events in their decomposition. The phenomenon is based on the observation that sentences containing the additive operator ke 'also' in Greek can give rise to a certain type of ambiguity. To illustrate, consider the sentence in (2). ${ }^{2}$ It asserts that John opened the window and gives rise to a presupposition that an eventuality involving some alternative to the window is true in the context. What type of eventuality? In the most accessible reading of sentence (2), the presupposition involves an event in which John opened something other than the window, as in (3a). We refer to such a presupposition as an Eventive Presupposition, as it requires the existence of a causative event. Crucially, we show that (2) can give rise to a second, weaker presupposition. In this case, the eventuality which figures in the presupposition of (2) is not an event, but a state; particularly, the state of something other than the window being open, as in (3b). We refer to this alternative presupposition as a Stative Presupposition (SP). We will use the short-hand 'Eventive-Stative ambiguities' to refer to the ambiguity of (2).

O Janis anikse ke to PARATHIRO.

the John opened also the window

'John opened the window too.'

(3) a. Eventive Presupposition: John opened something other than the window.

b. Stative Presupposition: Something other than the window is open.

The main aim of this paper is to show that an event-decompositional analysis is both necessary and sufficient to explain the existence of Stative Presuppositions. Event decompositional analyses of result verbs include an accessible constituent that denotes a predicate of states that additive operators can take scope over. Assuming that the level of verbal decomposition is syntax proper and that internal arguments can be integrated at a very low level as arguments of a purely stative component, Stative Presuppositions are predicted to arise without any further stipulation.

An event-decompositional analysis is not applicable to all result verbs, however. We investigate the distribution of SPs among different sub-classes of result verbs and observe that it is not uniform. Four major empirical observations emerge: (i) we detect no SPs with Incremental Theme verbs (IT, e.g., skarfalono 'climb', pleko 'knit') (with the possible exception of some creation verbs), (ii) we detect SPs with all Degree Achievement verbs (DA, e.g., stegnono 'dry', plateno 'widen'), (iii) Change Of State (COS) verbs (e.g., petheno 'die', ftiaxno 'fix'), Directed Motion (DM) verbs (e.g., beno 'enter', ftano 'arrive') and ditransitives (e.g., dhino 'give', pulao 'sell') show internal variation, (iv) manner (as in, e.g., pnigho 'drown', klotsao 'kick') bleeds SP licensing. To explain this distribution, we need to distinguish between structural

\footnotetext{
${ }^{2}$ We mark the intended associate of the additive operator in the English translation using italics. Here and throughout the paper we make no claim about the behavior of the corresponding English sentences.
} 
and non-structural differences between result verbs. We posit structural differences between three major sub-classes: IT verbs, DA verbs and the rest. In addition, we propose that there is non-structural internal variation within the classes of COS, DM and ditransitive verbs based on the properties of the idiosyncratic component of the decomposition.

We cast our analysis within the framework of Distributed Morphology (DM) where the idiosyncratic meaning component is related to the meaning of the root. Structural differences between result verbs are attributed to different types of roots and the way they interact with functional material in the verbal domain. In the case of IT verbs, eventive roots (i.e., roots denoting predicates of events) give rise to incrementality-based derivations. Degree Achievement verbs are built out of roots denoting measure functions, which can always give rise to degree-based eventdecompositional derivations. COS, DM, and ditransitive verbs are built out of stative roots (i.e., roots denoting predicates of states) and give rise to event-decompositional derivations. Treating roots as the locus of encyclopedic information explains both the lexical variation in SP licensing among COS, DM and ditransitive verbs and the effect of manner. Stative roots differ on whether they denote 'simple states' or 'result states' (i.e., states that come about as the result of some process). Stative roots with a manner component are necessarily of the latter type. The analysis of intra-class variation depends heavily on roots being the locus of the stative component of eventdecomposition. We discuss possible alternatives based on Small Clause structures and conclude that they lead to an overgeneration of SPs, at least for a language like Greek.

Finally, we strengthen our conclusions by showing that alternative semantic analyses that have been proposed to explain similar phenomena (most famously the restitutive readings of the adverbial again) without the need of syntactic eventdecomposition of the type argued for here fail in the case of additive operators. We thus conclude than an event-decompositional analysis is not only sufficient, but also necessary in order to explain the availability of SPs.

The paper is organized as follows. Section 2 presents an analysis of the Greek additive operator $k e$ 'also' that determines how the content of additive presuppositions is established in the case of Eventive Presuppositions. Section 3 offers a scopal analysis of Eventive-Stative ambiguities in an event-decompositional framework on the basis of the analysis of additive presuppositions in the previous section. It is thus shown that an event decompositional analysis is sufficient to explain the presence of Stative Presuppositions. Section 4 investigates the distribution of Stative Presuppositions among different classes of result verbs and establishes the major generalizations that capture this distribution. Section 5 analyzes this distribution in terms of the semantic content of roots and the way they interact with functional material introducing (relational) operators. Section 6 discusses and rejects possible syntactic alternatives based on Small Clause structures. Section 7 discusses and rejects semantic alternatives that make no reference to a syntactically accessible stative constituent. Event decomposition of the type defended in Sect. 5 is thus shown to be necessary in order to capture the presence of Stative Presuppositions. Section 8 presents some open issues and Sect. 9 concludes. 


\section{Additive presuppositions}

This section provides an analysis of the Greek additive operator ke 'also' outside the realm of Eventive-Stative ambiguities. The content of an additive presupposition is determined by the associate and the scope of the additive operator. ${ }^{3}$ Those are determined by the arguments of the additive operator. Association with focus in Greek is subject to the Focus Association Generalization in (4); Greek Focus Associating Operators (FAOs) adjoin to their associate and form a syntactic constituent with it (Chatzikyriakidis et al. 2015).

\section{Focus Association Generalization}

Focus Associating Operators in Greek are associated with their sister constituent.

An analysis of additive ke that readily conforms to the generalization in (5) is a 'twoplace' analysis, i.e., one in which the operator takes two arguments (cf. Wagner 2006 and references there for English only). The first argument is the associate, as per (4), the second the scope. Saturation of the second argument determines the propositional content of the additive presupposition. In the case of association with an individual denoting DP, the first argument of additive $k e$ is of type $e$ (individual). ${ }^{4}$ Accordingly, the second argument is of type $e, s t .^{5}$ To derive focus sensitivity, the meaning of additive $k e$ is made sensitive to alternatives (Rooth 1992). The meaning of additive $k e$, then, states that the property denoted by the second argument of the additive is true of the individual denoted by the associate (the assertoric component) and it is true of some alternative individual (the presuppositional component), as in (5). ${ }^{6}$

$$
\llbracket \operatorname{ke}(\mathrm{DP}) \rrbracket=\lambda \mathrm{P}_{\mathrm{e}, \mathrm{st}} \lambda \mathrm{i}_{\mathrm{s}}: \exists \mathrm{i}_{\mathrm{s}}, \exists \mathrm{x}_{\mathrm{e}} \in \llbracket \mathrm{DP} \rrbracket^{\mathrm{A}} \& \mathrm{x} \neq \llbracket \mathrm{DP} \rrbracket \& \mathrm{P}(\mathrm{x})\left(\mathrm{i}^{\prime}\right) . \mathrm{P}(\llbracket \mathrm{DP} \rrbracket)(\mathrm{i})
$$

Notice that after additive ke composes with a DP, the resulting constituent, which we call ke $D P$, has the type of a generalized quantifier. The scope of the quantifier determines what is the second argument of additive $k e$ and, therefore, the content of its presupposition. This predicts that scope ambiguities will be detectable in the content of the additive presupposition. This is borne out in examples like (6).

\section{O Petros theli na fai ke to KEIK.}

the Peter wants SUBJ eat also the cake

'Peter wants to eat the cake too.'

\footnotetext{
${ }^{3}$ The Greek particle $k e$ is a multi-functional element. See Canakis (1996), Tsiplakou (2005) for discussion of its several uses and Giannakidou (2007) for its use as part of the scalar additive akoma ke 'even'.

${ }^{4}$ To account for association with other types of constituents, one needs to generalize the entry in (5). Since all the examples used in the paper involve association with individual denoting DPs, we refrain from doing so.

${ }^{5}$ In anticipation of the account of Eventive-Stative ambiguities we are already casting the entry of the additive operator within an event semantics. Subscripted $s$ is the type of eventualities (events and states), $i$ is a variable over eventualities. We reserve the variable $e$ for events and $s$ for states.

${ }^{6}$ For ease of presentation, we assume direct focus sensitivity (Rooth 1985), i.e., we assume that the meaning of additive ke makes direct reference to Focus Semantic Values. We also assume an existential (Karttunen and Peters 1979), rather than an anaphoric (Kripke 1990), presupposition. These choices are not material for current purposes.
} 
(7) a. Embedded Clause Presupposition: Peter has eaten something other than the cake.

b. Matrix Clause Presupposition: Peter wants to eat something other than the cake.

In all environments ke DP exhibits the same scopal behavior as quantificational DPs. Consider, for example, scopal interactions between two quantificational DPs. In the SVO order, quantificational DPs in the subject position necessarily out-scope quantificational DPs in the object position, as shown in (8). VSO orders are scopally ambiguous, as shown in (9). Similarly, ke DPs in pre-verbal subject positions necessarily out-scope indefinites in object position, as in (10). ke DPs in post-verbal subject positions, on the other hand, can be out-scoped by indefinites in object position, as in (11) ${ }^{7}$

Enas fititis anikse kathe parathiro.

$$
\exists>\forall / * \forall>\exists
$$

a student opened every window

'A student open every window.'

Anikse enas fititis kathe parathiro.

$$
\exists>\forall / \forall>\exists
$$

opened a student every window

'A student open every window.'

Ke o Janis anikse ena parathiro.

ke $D P>\exists /{ }^{*} \exists>$ ke $D P$ also the John opened a window 'John opened a window too.'

Anikse ke o Janis ena parathiro.

ke $D P>\exists / \exists>$ ke $D P$ opened also the John a window 'John opened a window too.' ke $D P>\exists$ Presupposition: Someone other than John opened some window. $\exists>$ ke DP Presupposition: Someone other than John opened the same window.

A further consequence of the analysis is that the scopal position of ke DP will uniquely determine the content of the presupposition; any material in the scope of ke DP will necessarily be part of the additive presupposition. To illustrate, consider an example of association with the subject that also includes a manner adjunct, of the type that is standardly taken to adjoin very low in the verbal projection, as in (12). ${ }^{8}$

Ke o JANIS anikse me dhinami to parathiro. also the John opened with force the window 'John opened the window with force too.'

a. Assertion: John opened the window with force

\footnotetext{
${ }^{7}$ Scopal interactions between quantificational DPs/ $k e D P$ s and negation also show the same pattern. Known restrictions on reconstruction of quantificational DPs also apply to ke DPs. We omit these data for reasons of space. We have found no environment in which ke DPs behave differently than quantificational DPs, with the possible exception of the 'scope freezing effects' discussed in fns. 21 and 37.

${ }^{8}$ Note that the order Verb PP Object ensures that the modifier is located within the VP and in the scope of the subject.
} 
b. Presupposition with adjunct: Someone other than John opened the window with force.

c. \#Presupposition without adjunct: Someone other than John opened the window.

Example (12) is felicitous in the context in (14), which entails that someone other than John opened the window with force, but infelicitous in the context in (15), which does not. This is not expected if (12) could give rise to the weaker presupposition in $(13 \mathrm{c})$. We conclude that the content of the additive presupposition must include every part of the meaning of its scope. In fact, we can make the same point even with examples that do not include a manner adverb. In every case no presuppositions can be generated that are asymmetrically entailed by the presuppositions we have identified. The point here is that an analysis of additive presuppositions must not only predict which presuppositions do, in fact, arise, but also which presuppositions cannot arise. The scopal analysis cuts the pie correctly.

Context for presupposition with adjunct:

Mary forcefully opened the window. The wind closed it. So ...

Context for presupposition without adjunct:

Mary delicately opened the window. The wind closed it. So ...

In this section we have provided the basics of an analysis of additive presuppositions. We have established that the content of the additive presupposition is determined uniquely by the arguments of the additive operator (i.e., its associate and its scope) and that $k e D P$ is a quantificational DP subject to scopal ambiguities.

\section{A scopal analysis of Eventive-Stative ambiguities}

This section argues in favor of syntactic event decomposition of at least some lexical predicates, on the basis of the existence of Eventive-Stative ambiguities. We show how a scopal analysis predicts the existence of Eventive-Stative ambiguities without further stipulation the moment a node denoting a predicate of states is assumed to be part of the syntactic decomposition of the relevant predicates.

\subsection{The Stative Presupposition}

The main empirical observation of the current paper is that examples like (2), repeated here in (16), are felicitous in contexts that do not satisfy the Eventive Presupposition we have considered so far, nor, indeed, any other imaginable presupposition that requires the existence of an alternative event. Consider, for example, the context in (17).

O Janis anikse ke to PARATHIRO.

the John opened also the window

'John opened the window too.' 


\section{Context for Stative Presupposition:}

The door of the room had always stood open since it wasn't installed properly. This was a very warm day, so ...

The Eventive Presupposition is clearly not satisfied in this context since neither John nor anyone else opened anything other than the window. Still, (16) is felicitous in the context of (17). We take this to mean that (16) can give rise to a weaker presupposition, one that is satisfied in the context of (17). What could this presupposition be? Given association with the object, we know that the relevant presupposition should regard some alternative to the window. The only relevant alternative in the context is the door for which the only thing we learn is that it was in a state of being open. We propose that this is exactly the relevant additive presupposition in this case. Since it requires the existence of a state, we refer to it as a Stative Presupposition.

Stative Presupposition: Something other than the window is open.

Notice that Stative Presuppositions pass regular diagnostics for presuppositional status. To give one indicative example, SPs escape the scope of negation, as in (20).

Context: The door of the room had always stood open since it wasn't installed properly. Even though this was a very warm day, ...

o Janis dhen anikse ke to PARATHIRO.

the John not opened also the window

'John didn't open the window too.'

\subsection{The scopal analysis}

Since we know that the content of an additive presupposition is determined by the arguments of the additive operator, it follows that there must exist a syntactically accessible node that denotes a predicate of states and is the argument of ke DP. Moreover, the associate of $k e$ should be an argument related to this stative predicate. To achieve that we need to decompose the VP into an eventive and a stative component. Crucially, the internal argument should be an argument of the stative predicate. There are many possible syntactic decompositions that satisfy these minimal requirements. For the time being we will provide an analysis along the lines of (21) for transitive result verbs, where $D P_{\text {int }}$ is the internal argument and $D P_{\text {ext }}$ is the external argument.

$$
\text { [vp DP } \left.\left.\left.\left.\text { ext }_{\text {[ AGENT [ CAUSE [ DP }} \text { int }\left[\text { Pred }_{\text {Stative }}\right]\right]\right]\right]\right]
$$

We assume two operators on top of the stative layer, CAUSE and AGENT. CAUSE takes a predicate of states as its argument and introduces a causing relation between an event and a state, as in (22). We assume Lewis' counterfactual theory of causation, along the lines of Kratzer (2005) dispensing with a BECOME operator. ${ }^{9}$ Roughly speaking, an event $e$ is an event of causing a state $s$ if $s$ wouldn't have occurred if $e$

\footnotetext{
${ }^{9}$ See also Schäfer (2008) and Alexiadou et al. (2006, 2015), especially on how anti-causatives should be treated in a system that dispenses with BECOME altogether, and Martin and Schäfer (2014) for an overview of analyses of causative verbs.
} 
hadn't and $s$ is a part of $e$. We assume that the external argument is introduced by the AGENT operator in (23) within the extended projection of the verb (Marantz 1992; Kratzer 1996; a.m.o.).

$$
\begin{aligned}
& \llbracket \text { CAUSE } \rrbracket=\lambda p_{s t} \lambda e_{s} \exists s . p(s) \& \text { e is an event of causing } \mathrm{s} \\
& \llbracket \text { AGENT } \rrbracket=\lambda p_{s t} \lambda x_{e} \lambda e_{s} \cdot p(e) \& \operatorname{agent}(x)(e)
\end{aligned}
$$

For a verb like Greek anigho 'open', the stative predicate is OPEN, as in (24), with the meaning in (25). Crucially, the internal DP is an argument of OPEN.

$$
\begin{aligned}
& \left.\left.\left[\mathrm{vP} 4 \mathrm{DP}_{\mathrm{ext}}\left[\mathrm{vP3} \text { AGENT [vP2 CAUSE [vP1 DP }{ }_{\text {int }}[\mathrm{OPEN}]\right]\right]\right]\right] \\
& \llbracket \text { OPEN } \rrbracket=\lambda \mathrm{x}_{\mathrm{e}} \lambda \mathrm{s}_{\mathrm{s}} \cdot \operatorname{open}(\mathrm{x})(\mathrm{s})
\end{aligned}
$$

OPEN is a stative constituent of the right type to compose directly with ke DP allowing a Stative Presupposition to be derived without further stipulation. Consider the partial derivation of (16) in (27), based on the structure in (26). Composing ke DP with the stative predicate fixes the content of the presupposition to a Stative Presupposition. This is passed on via presupposition projection and becomes the presupposition of (16).

\section{[vP4 [DP O Janis] [vP3 AGENT [vP2 CAUSE [vP1 [DP ke to parathiro] [ OPEN ]]]]]}
a. $\llbracket$ ke to parathiro $\rrbracket=\lambda \mathrm{P}_{\mathrm{e}, \mathrm{st}} \lambda \mathrm{i}_{\mathrm{s}}: \exists \mathrm{i}{ }_{\mathrm{s}} \exists \mathrm{x}_{\mathrm{e}} \in \mathrm{D}_{\mathrm{e}} \& \mathrm{x} \neq$ the_window \& $\mathrm{P}(\mathrm{x})(\mathrm{i})$ ). $\mathrm{P}($ the $-w i n d o w)(\mathrm{i})$
b. $\llbracket$ OPEN $\rrbracket=\lambda x_{\mathrm{e}} \lambda \mathrm{s}_{\mathrm{s}}$. open $(\mathrm{x})(\mathrm{s})$
c. $\llbracket \mathrm{VP} 1 \rrbracket=\lambda \mathrm{s}_{\mathrm{s}}: \exists \mathrm{s}_{\mathrm{s}}{ }_{\mathrm{s}} \exists \mathrm{x}_{\mathrm{e}} \in \mathrm{D}_{\mathrm{e}} \& \mathrm{x} \neq$ the_window \& open(x)(s'). open(the_window)(s)

Eventive Presuppositions are generated when ke DP takes scope over an eventive constituent. We assume a standard theory of Quantifier Raising (QR), as in Heim and Kratzer (1998), as a scope-taking mechanism. There are two available nodes that denote predicates of events proper and can be the target of QR in the proposed decomposition, $\mathrm{VP}_{2}$ and $\mathrm{VP}_{4}$ in (24). $\mathrm{QR}$ to $\mathrm{VP}_{2}$ as in (28a) gives rise to a 'subjectless' Eventive Presupposition (Something caused something other than the window to open), since AGENT is not in the scope of the additive operator. QR to $\mathrm{VP}_{4}$ as in (28b) gives rise to the regular Eventive Presupposition we have considered so far (John opened something other than the window), as shown in the partial derivation of (28b) in (29).

(28) a. [VP6 [DP O Janis] [vP5 AGENT [VP4 [DP ke to parathiro] [VP3 1 [vP2 CAUSE [VP1 $\mathrm{t}_{1}$ [ OPEN ]]]]]]]

b. [VP6 [DP ke to parathiro] [VP5 1 [VP4 [DP O Janis] [vP3 AGENT [vP2 CAUSE [vP1 $\mathrm{t}_{1}$ [ OPEN ]]]]]]]

(29) a. $\quad$ VP5 $\rrbracket=\lambda x_{e} \lambda e_{s} . \exists s$. open(x)(s) \& e is an event of causing $s \&$ $\operatorname{agent}(\mathrm{j})(\mathrm{e})$

b. $\quad \llbracket \mathrm{VP} 6 \rrbracket=\lambda \mathrm{e}_{\mathrm{s}}: \exists \mathrm{e}_{\mathrm{s}} \exists \mathrm{s} \exists \mathrm{x}_{\mathrm{e}} \in \mathrm{D}_{\mathrm{e}} \& \mathrm{x} \neq$ the_window \& open(x)(s) \& e' is an event of causing s \& agent(j)(e'). $\exists$ s. open(the_window)(s) \& e is an event of causing $s \&$ agent $(j)(e)$ 
One might wonder whether the derivations in (28) are necessary, given that any context in which an Eventive Presupposition is satisfied is a context in which a Stative Presupposition is also satisfied; in a context in which John opened something other than the window, something other than the window is open. Evidence for Eventive Presuppositions as distinct presuppositions comes from the existence of word orders that block Stative Presuppositions but still allow Eventive Presuppositions, a type of argument familiar from the literature on the Repetitive-Restitutive ambiguity of again (von Stechow 1996). For example, fronted ke DPs in a left-peripheral position, as in (30), do not generate SPs, but do generate EPs. ${ }^{10}$

\section{Ke to PARATHIRO anikse o Janis. also the window opened the John 'John opened the window too.'}

We have seen that the generation of SPs requires a decomposition of at least some result verbs that (i) contains a stative component, (ii) which is syntactically accessible, and (iii) allows the object DP to take scope over it. These basic requirements can be achieved under different implementations of event-decompositional analyses. Some choices will be immaterial for present purposes. For example, we could assume that the internal argument is introduced via some operator, e.g., HOLDER, as in Lohndal (2014), rather than being a direct argument of the root. A movement account of the internal argument, where the DP moves from a position inside the stative constituent to a higher position inside the domain of verbal decomposition (cf. Ramchand 2008) could also work, depending on the properties of the movement mechanism. Similarly, one could dispute the necessity of two separate operators (CAUSE and AGENT) or choose to analyze causative verbs in terms of an operator PROCESS, rather than CAUSE. ${ }^{11}$ As far we can see, none of these choices affects the generation of SPs.

At the same time, however, the three basic requirements immediately rule out a number of other analyses for SP-generating result verbs. To give some examples, they rule out analyses that posit no stative component in the decomposition (e.g., incrementality-based analyses as in Krifka 1989; Rothstein 2004; Borer 2005; degree- or vector-based scalar analyses like, Hay et al. 1999; Kennedy and Levin 2008; Zwarts 2006; Winter 2006), analyses that do contain a stative component but one that is not syntactically accessible (e.g., Dowty 1979; Rappaport Hovav and Levin 2010; Hale and Keyser 1993; a.o.), as well as analyses that might contain a syntactically accessible stative component, but one that the internal argument cannot exclusively take scope over (e.g., Parsons 1990; the 'process'-based analyses of Pietroski 2005; Williams 2005; the 'complex predicate' analyses of Neeleman 1994; Neeleman and Van de Koot 2002; and the Control-based analyses of Beck and Johnson 2004; von Stechow 2007; a.o.). In order to maintain such analyses for SP-

\footnotetext{
${ }^{10}$ Evidence from non-monotonic environments that break the entailment relation between Eventive and Stative Presuppositions point to the same conclusion. See Lechner et al. (2015) for relevant discussion in the context of again-ambiguities. Their arguments apply equally to the case of additive operators.

${ }^{11}$ Notice, however, that all 'process'-based analyses we are aware of assume that the internal argument is an argument of the process rather than the state. This feature of these analyses would need to be revised. Copley and Harley's (2015) analysis, which is cast in a force-theoretic framework that makes use of situations rather than eventualities, also passes the syntactic requirements for SP-licensing.
} 
generating result verbs we would need to posit some mechanism for generating SPs that is in some way or other distinct from the scopal mechanism that generates regular Eventive Presuppositions and regulates their distribution. We will consider a number of such possible analyses in Sect. 7 and argue that they are inadequate. A key deficiency they all exhibit is a failure to adequately predict the distribution of SPs among result verbs. It is this issue we now turn to.

\section{The distribution of Stative Presuppositions}

This section investigates the distribution of Stative Presuppositions (SPs) among different classes of result verbs. We will be referring to verbs that can give rise to SPs in the presence of a presupposition trigger like the additive operator ke 'also' as SPgenerating or SP-licensing verbs. Our discussion is structured around the definition of 'result verbs' in Levin and Rappaport Hovav (2014). According to that definition, 'result verbs' are verbs that denote scalar change; i.e., they involve an entity undergoing change in some scalar attribute. All verbs discussed in this section then describe eventualities in which the referent of one of the verb's arguments changes along some dimension as it participates in the relevant event. ${ }^{12}$ Rappaport Hovav (2014) provides a further three-way classification based on several grammatical criteria. She distinguishes between Incremental Theme (IT) verbs, Change Of State (COS) verbs, and Directed Motion (DM) verbs. Her main point is to argue for a fundamental difference between IT verbs, on the one hand, and COS and DM verbs, on the other. Whereas the scalar property is provided by the internal argument in the case of IT verbs, it is part of the verbal meaning, in the case of COS and DM verbs. This difference is argued to manifest itself in the behavior of different grammatical phenomena. In what follows, we briefly introduce each class based on the classification of Rappaport Hovav (2014) and investigate its behavior with regard to the licensing of SPs. We add in our discussion ditransitive predicates, in both the Prepositional Object Construction (POC) and the Dative Object Construction (DOC).

All verbs that appear in examples in the main text have been checked with eleven native speakers of Greek. All examples were presented to our informants in oral form in order to be able to control for prosody in face-to-face sessions. For each verb that we checked, we indicate in parentheses the number of speakers that judged the relevant example felicitous in the given context, a context that supports a Stative Presupposition but does not support an Eventive Presupposition. We extrapolate about the behavior of similar verbs based on the classification we are using and our own intuitions (both authors are native speakers of Greek). ${ }^{13}$

\footnotetext{
${ }^{12}$ Notice that achievement predicates are incorporated into the class of 'result verbs' as defined in Rappaport Hovav and Levin (2010). The idea is that achievement predicates are also scalar terms, but scalar terms that 'describe values on scales that consist of just two values' (Beavers 2013:690). In that sense, they are scalar, but non-gradable.

${ }^{13}$ Notice that in all the examples the prosody required by association with focus is distinct from default prosody. In that way we exclude the possibility that the additive associates with some wider constituent, e.g., the VP. In some cases, this is the result of the associate not being in sentence-final position. In other cases, we achieve the same result by association with DP-internal material.
} 


\subsection{Incremental Theme (IT) verbs}

In the case of IT verbs the relevant change can be associated with the volume or extent of the referent of the internal argument, so that in most cases there is actual change in the mereological constitution of the theme argument in the course of the event. This is definitely the case for creation and consumption verbs like ravo 'saw', pleko 'knit', troo 'eat', etc. The defining characteristic of IT verbs and what distinguishes them from the other sub-classes of result verbs in Rappaport Hovav's typology is the fact that the relevant scale is provided by the theme argument, rather than the verb.

Consider first consumption verbs as in the prototypical case of troo ena milo 'eat an apple'. The nature of the result state of an event of consumption is not easy to identify. Moreover, under normal circumstances the relevant state depends on some preceding process, as described by the verb itself (a process of eating, devouring, etc.). This creates a difficulty in checking for SPs, as it is difficult to create contexts in which a SP is licensed and a subject-less/ intermediate presupposition is not licensed (perhaps via accommodation). We have found that the easiest and most reliable way to overcome such difficulties is to consider scenarios in alternative worlds in which it is possible for things and state-of-affairs to spontaneously come into existence, e.g., dream-worlds or fantasy worlds where magic is possible. Consider the context in (31). To the extent that we can take the presence of an apple's flesh in someone's stomach to indicate the result of the process of eating an apple, then a SP is satisfied in this context. Yet, the target sentence in (32) is infelicitous in this case (only 3 out of 11 speakers judged it felicitous). We have similar judgments for all consumption verbs and have failed to create any context that would license a SP. ${ }^{14}$

\section{Context for Stative Presupposition:}

Hermione was holding a green apple. With a movement of her wand, she made the flesh of a red apple appear in her stomach. Later ...

\#efaje ke to PRASINO milo.

ate.3SG also the green apple

'She ate the GREEN apple too.'

In their telic readings, IT verbs of creation identify a clear endstate in which an object is in existence. Consider for example the VP pleko ena kitrino pulover 'knit a yellow sweater' in a context where the speaker describes a dream of theirs, as in (33). Use of ke 'also' in (34) was judged felicitous by 7 out of 11 speakers. The question mark indicates that a minority of speakers didn't share this intuition. It is also the case that many speakers were less confident about their judgment. This conforms to our own experiences in judging this and similar cases. Our intuitions can differ depending on the choice of context and creation verb, in a way that doesn't seem to show any systematicity.

Context for Stative Presupposition:

Last night in my dream I was walking down a corridor when all of sudden a

\footnotetext{
${ }^{14}$ Note that there is no effect of context (real vs. fantasy/ dream-world) in the licensing of SPs, only an effect of verb type. Verb-types behave identically across contexts. All the verbs claimed to license SPs throughout the paper also do so in the dream-worlds considered here.
} 
red sweater and a knitting supply kit appeared in front of me. I took everything with me and a bit later I sat down and ...

$$
\begin{aligned}
& \text { ?epleksa ke ena KITRINO pulover. } \\
& \text { knitted.1SG also a yellow sweater } \\
& \text { 'I knitted a yellow sweater too.' }
\end{aligned}
$$

In other cases, the relevant measure of change is a path. Manner of motion verbs can take direct accusative arguments that specify the path that the subject traverses in the course of the event. Crucially, in these cases too, the measure of change is uniquely associated with the argument, not the verb. The predicates describe events in whose endstate some specific and identifiable state obtains; in the case of, e.g., skarfalono to dentro 'climb the tree' the endstate is one in which the climber is at the top of the tree. In this case no SP is generated, as shown in (36) for association with the subject ( 0 out of 11 speakers) and in (38) for association with the direct object (3 out of 11 speakers). In our judgment, VPs like perpatao ton diadromo 'walk the corridor', trexo ena mili 'run a mile', kolimbao ena jiro 'swim a lap', etc. also clearly license no SPs. ${ }^{15}$ We conclude that with the possible exception of some creation verbs, IT verbs fail to license SPs.

\section{Context for Stative Presupposition:}

Last night in my dream I was walking in a desert when all of sudden a tree appeared in front of me with a cat sitting on top of it. In order to catch the cat...

$$
\begin{aligned}
& \text { \#skarfalosa ke EGHO to dhendro. } \\
& \text { climbed.1SG also I the tree } \\
& \text { 'I climbed the tree too.' }
\end{aligned}
$$

\section{Context for Stative Presupposition:}

Last night in my dream I suddenly found myself on top of a small tree. A big tree was right next to it. I climbed down and ...

\#skarfalosa ke to MEGHALO dhendro.
climbed.1SG also the big tree
'I climbed the big tree too.'

\subsection{Change of State (COS) verbs and Degree Achievements}

Change Of State (COS) verbs describe eventualities in which a referent of one of their arguments undergoes change along a scalar property. Importantly, the scalar property is lexically encoded in the verb itself (Rappaport Hovav 2014), not the argument. This is the case with verbs built on a de-verbal base (i.e., a root that can only form a verb and no other category), as well as with verbs built on a de-adjectival base (i.e., verbs built on roots that can also form adjectives). We will reserve the label COS verbs for the first class and call the second class of verbs Degree Achievements.

\footnotetext{
${ }^{15}$ Beavers and Koontz-Garboden (2017) treat English climb as a COS verb which incorporates a manner component. For reasons of consistency, we will side with the treatment in Rappaport Hovav (2014). Nothing crucial hinges on this choice, as far as the licensing of SPs is concerned.
} 
Consider first COS verbs. We have already seen the example of anigho 'open', which does license a SP. ${ }^{16}$ Other such verbs that readily license SPs are klino 'close' (10 out of 11 speakers) and petheno 'die' (8 out of 11 speakers), as shown in (40a). The causative skotono 'kill', built on a different root than petheno 'die', on the other hand, is not a SP-generating verb (3 out of 11 speakers), as shown in (40b).

Context for Stative Presupposition:

Last night in my dream I was walking in a desert when all of a sudden two lizards appeared in front of me; a dead green one and a brown one which was wounded and about to die. I buried them both once ...
a. pethane ke i KAFE savra.
died also the brown lizard
'The brown lizard died too.'
b. \#skotosa ke tin KAFE savra.
killed.1SG also the brown lizard
'I killed the brown lizard too.'

Other COS verbs that do not license SPs are ftiaxno 'fix' (3 out of 11 speakers) and epidiorthono 'repair' (0 out of 11 speakers), as shown in (42). In our judgment, spao 'break' and rajizo 'crack' are also not SP verbs. The verb ljono 'melt' gave mixed results (5 out of 11 speakers).

\section{Context for Stative Presupposition:}

Last week, Mary bought two new TVs, a small one and a big one. Three days later the small TV was still working fine, but the big one wasn't. Very upset, Mary brought out her tools and ...

\#eftiakse / epidhiorthose ke tin MEGHALI tileorasi.
fixed.3SG fixed.3SG also the big television
'She fixed the big television too.'

Another class of COS verbs that do not license SPs are result verbs that have been argued to include a manner component (Beavers and Koontz-Garboden 2012), like the manner of killing verbs pnigho 'drown' (1 out of 11 speakers) and apokefalizo 'decapitate' ( 0 out of 11 speakers) in (43), judged in the context of (39). ${ }^{17}$ In our judgment, kremao 'hang' behaves similarly.

\#Epniksa / \# Apokefalisa ke tin KAFE savra.
drowned.1SG decapitated.1SG also the brown lizard
'I drowned/ decapitated the brown lizard too.'

Degree Achievements (DA), on the other hand, show no such variability. They all readily generate SPs regardless of their scalar properties. A total Degree Achievement predicate, like steghnono 'dry', is based on scales with a maximum degree; a

\footnotetext{
${ }^{16}$ Notice the difference with English open, which is a Degree Achievement verb, in the sense defined here.

${ }^{17}$ These verbs pass both the manner and result diagnostics discussed in Beavers and Koontz-Garboden $(2012,2017,2020)$. We have omitted the relevant data for reasons of space. See Sect. 5.6 for some more discussion.
} 
sentence like The shirt dried is most prominently taken to mean that the shirt reached a maximum degree of dryness in the course of the event. Total DAs in Greek generate SPs, as exemplified in (45) with steghnono 'dry' (11 out of 11 speakers). Addition of the additive operator gives rise to a presupposition according to which something other than the red shirt is maximally dry. In our judgment, all total DAs clearly behave similarly.

\section{Context for Stative Presupposition:}

Yesterday, John bought two new shirts, a yellow one and a red one, but dropped them near some water right after he got out of the store. The yellow shirt stayed dry, but the red one got wet. At home, he hung them both in the sun and ...

\section{steghnose ke to KOKINO pukamiso.}

dried.3SG also the red shirt

'The red shirt dried too.'

Relative Das such as plateno 'widen' are based on open scales, i.e., scales with no minimum or maximum degree; a sentence like The river widened is most prominently taken to mean that the river increased in width (without any implication with regard to the degree of width that it had acquired by the end of the event). Relative DAs can also give rise to a SP, as shown in (47) for akriveno 'become (more) expensive' (11 out of 11 speakers). The relevant presupposition is that something other than the bread is expensive relative to some contextual standard, the same standard as the one used by the corresponding adjective akrivos 'expensive' in the same context. This points to relative DAs having an additional reading akin to 'become expensive.' In our judgment, all relative DAs behave similarly.

(46) Context for Stative Presupposition:

Bread and milk are considered expensive in Greece if they cost more than 1 Euro (per kilo). John opened a new bakery in January and set the price of milk to 1,20 Euro and that of bread to 0,80 Euro. One month later, John raised the price of bread to 1,10 Euro per kilo, so that ...

$$
\text { akrivine ke to PSOMI ston furno tu Jani. }
$$

expensive.3SG also the bread at.the bakery the John

'The bread became expensive too in John's bakery.'

We have observed a basic distinction between COS verbs and Degree Achievements; whereas all DAs are SP-generating verbs, not all COS verbs are such. Moreover, we have observed that the properties of the underlying scale do not affect the ability of DAs to license SPs verbs; i.e., both total and relative DAs license SPs. However, licensing of SPs depends on the availability of a reading of DAs that can be paraphrased with 'become A,' where A is the corresponding adjective associated with the DA. In this case, the upper bound is associated with the adjectival standard. The COS verbs we have considered are all associated with bounded scales, since the majority of them rely on two-point scales. Yet not all of them license SPs. So, whereas being associated with (upper) bound scales is a necessary condition for SP-licensing, it is not a sufficient one, as seen in the case of COS verbs. 


\subsection{Directed motion (DM) verbs}

We now move to Directed Motion (DM) verbs; i.e., verbs that are lexically associated with path scales. DM verbs also fall under the Levin and Rappaport definition of 'result verbs,' since they encode scalar change. Particularly, DM verbs encode change along a path, so that the events in the denotation of a DM verb all involve a change in the location of an individual (the theme argument) along a path from its location at the beginning of the event to its location at the end of the event. Unlike in the case of COS verbs, the relevant scalar property is not fully lexicalized by the verb. The relevant path is built with the help of a reference object (RO), which is usually introduced by a Prepositional Phrase. It is the points of location between the theme argument at the beginning of the event and the RO that form the relevant path. Although the scalar dimension is obviously always the same (location), DM verbs can differ in a number of ways (Rappaport Hovav 2014). They can differ in how the relevant path is built; the RO might be lexicalized in the verb or be recoverable from context, movement can be towards or away from the $\mathrm{RO}$, and different verbs might require different portions of the path to be traversed. Also, like COS verbs, the relevant scales can be twoor multi-point. Multi-point scales can differ in whether they are upper-bounded or not (since the location of the theme at the beginning of the event provides the initial location of the path, they will always be bounded at the lower end).

In all the Greek examples discussed in this section we will be considering cases of clearly upper-bound paths. The upper bound of the path is introduced by a locational PP. In that way, all the predicates are telic and describe events at whose endpoint some specific and identifiable state obtains. We begin with non-gradable DM verbs; i.e., verbs built on two-point scales. The theme is either located at a point contiguous with the RO introduced by a Prepositional Phrase or not. The verb beno 'enter' is a SP verb (10 out of 11 speakers), as shown in (49). The verb ftano 'arrive' in (51) shows mixed results ( 5 out of 11 speakers). In our own judgment, vjeno 'exit' behaves like beno 'enter', whereas fevgho 'leave' and anaxoro 'depart' clearly fail to generate SPs.

(48) Context for Stative Presupposition:

Charlie owns a puppy and a kitten. Both were born in his apartment, the puppy in the kitchen and the kitten in the living room. Both stayed in their own rooms, until, three days after they were born, ...

(49) bike ke to KUTAVI sto saloni. entered also the puppy at.the living room

'The puppy entered the living room too.'

(50) Context for Stative Presupposition:

John and Mary met through some dating app. After interacting on-line for some time, they decided to meet in person. John lives in Berlin, but Mary lives in Paris. They first went out for a drink together two days ago after ...

?eftase ke o JANIS sto Parisi.

arrived also the John at.the Paris

'John arrived at Paris too.' 
Gradable DM predicates, for which the RO must be provided by a PP (or, in some cases, by the context), such as epistrefo 'return' do not give rise to a SP (2 out of 11 speakers), as shown in (53). The verb pigeno 'go' shows mixed behavior (6 out of 11 speakers), as shown in (55). In our own judgment, erxome 'come', pijeno 'take', and ferno 'bring' are also SP verbs.

\section{Context for Stative Presupposition:}

John and Mary, a couple, were both born in Paris. John loves Paris and has never left the city. Mary spent some time in Berlin for work last year. They got married two days after...

$$
\begin{aligned}
& \text { \#epestrepse ke i MARIA sto Parisi. } \\
& \text { returned also the John at.the Paris } \\
& \text { 'Mary returned to Paris too.' }
\end{aligned}
$$

\section{Context for Stative Presupposition:}

John and Mary met through some dating app and decided to meet in person. John lives in Berlin, but Mary lives in Paris. They first went out for a drink together two days ago after...

\section{pije ke o JANIS sto Parisi.}

went also the John at.the Paris

'John went to Paris too.'

Finally, Rappaport Hovav (2014) identifies a class of DM verbs, which she argues, lexicalize all the components of the path, including the RO. These are verbs encoding motion along a vertical axis. The RO in this case seems to be the source of gravity. Rappaport Hovav claims that the corresponding paths are not necessarily bounded. Introduction of a PP, however, can specify a RO whose location will serve as the upper bound of the path. Again, we find variation in the licensing of SPs. The verb aneveno 'ascend' is a SP-generating verb (8 out of 11 speakers), as shown in (57), whereas pefto 'fall' is clearly not (1 out of 11 speakers), as shown in (59). In our own judgment kateveno 'descend', rixno 'drop' also license SPs.

(56) Context for Stative Presupposition:

John owns a puppy and a kitten. Both were born in his house, the puppy on the first floor and the kitten on the second floor. The two of them had never met, until, three weeks after they were born, ...

anevike ke to KUTAVI ston deftero orofo.

ascended also the puppy at.the second floor

'The puppy went up to the second floor too.'

(58) Context for Stative Presupposition:

John owns a puppy and a kitten. The puppy was born in a big hole in the garden, in which it has spent all his days since. The kitten was born in the shed. The two of them had never met, until, three weeks after they were born,

\#epese ke to GHATAKI stin tripa. fell.3SG also the kitten at.the hole

'The kitten fell in the hole too.' 
Finally, note that Greek is a verb-framed language in the typology of Talmy (1985) (Horrocks and Stavrou 2003, 2007, a.o. for Greek). As such, it fails to license directed motion with manner of motion verbs; i.e., verbs that specify the manner of motion, but not the path of motion, as in (60).

(60) O Janis perpatise/ sirthike/ horepse sto parko. the John walked crawled danced at.the park \#'John walked/ crawled/ danced to the park.'

'John walked/ crawled/ danced at the park.'

As is well-known there are some exceptions (see, e.g., Beavers et al. 2010 and references therein). Verbs like trexo 'run', kilao 'roll' can express directed motion, as in (61). It is generally agreed, however, that in such uses the verbs change their meanings; e.g., trexo acquires the meaning 'rush to.' In this use a manner component is retained ('with haste'), but it has nothing to do with the way John moved; (61) is true even if, e.g., John went to the hospital by car.

O Janis etrekse sto nosokomio.

the John ran at.the hospital

'John rushed to the hospital.'

It seems, then, that we are dealing with result verbs that have an additional manner component. Crucially, SPs are not generated (0 out of 11 speakers), as shown in (63) for treho 'run'.

(62) Context for Stative Presupposition:

John's daughter was born in the hospital yesterday morning and has stayed there since. John was not in town yesterday. This morning, after he landed at the airport, ...

(63) \#etrekse ke AFTOS sto nosokomio. ran.3SG also he at.the hospital

'He rushed to the hospital too.'

To summarize, we have observed that although association with an (upper) bound path is a necessary condition for SP-licensing, not all telic DM verbs license SPs. The observed variation cannot be reduced to other scalar properties of the relevant predications (two- vs- multi-point scales) or structural properties like the mode of introduction of the RO. Finally, SP licensing is bled in the presence of a manner meaning component.

\subsection{Ditransitives}

We show in this section that ditransitives verbs in Greek, both in the Prepositional Object Construction (POC) and the Double Object Construction (DOC) can give rise to Eventive-Stative ambiguities. To the best of our knowledge, the first discussion of relevant data appears in Bruening (2010), where it is shown on the basis of the 
examples in (64) (see Bruening 2010:(60) and (86)) that English too can associate with a Goal argument in the DOC and give rise to a SP. ${ }^{18}$

a. Johnny came to school with a lollipop. All the other kids were jealous, so the teacher gave each of them a lollipop too.

b. I'm jealous that you always have such a calm demeanor. Can you give me a calm demeanor too?

We expand this observation by showing that SPs can arise in both POCs and DOCs in Greek, both in cases of association with the Goal argument and the Theme argument and regardless of whether the relevant state is one of possession (' $x$ has $y$ ') or location (' $\mathrm{x}$ is at $\mathrm{y}$ '). The result states of POCs are either states of possession, states of location, or both. The result states of DOCs are always states of possession (see Beavers 2011a and references there). In all cases we are dealing with two-point scales; $x$ either has/ is at $\mathrm{y}$, or not.

We consider first Prepositional Object Constructions (POCs); i.e., cases in which the Goal argument of a ditransitive verb is introduced by a Prepositional Phrase headed by the preposition $s(e)$ 'at'. For a verb like dhino 'give' the result state is always one of possession. SPs are licensed both in cases of association with the goal argument (9 out of 11 speakers), as shown in (66), and in cases of association with the theme argument (10 out of 11 speakers), as shown in (68). ${ }^{19}$ Other ditransitive verbs of caused possession that, in our judgment, behave like dhino 'give' are paradhino 'deliver/hand in', pernó 'pass' and paraxoro 'cede x to y'. A verb like pulao 'sell', on the other hand, licenses no SPs, both in cases of association with the goal argument ( 0 out of 11 speakers) and in cases of association with the theme argument ( 0 out of 11 speakers). Other verbs of this class that, in our judgment, behave like pulao 'sell' are dhanizo 'lend' and xarizo 'donate/give away'. 20

\section{Context for Stative presupposition:}

Last night in my dream I was walking down an empty road holding a bunch of tennis balls. All of a sudden, a girl and a boy materialized in front of me. The girl had a tennis ball in her possession, the boy didn't have anything. He seemed to be sad about it so ...

edhosa / \# pulisa ke sto AGHORI mia bala.
gave.1SG sold.1SG also at.the boy a ball
'I gave / sold a ball to the boy too.'

\footnotetext{
${ }^{18}$ We thank Florian Schäfer (p.c.) for pointing us to Bruening's observation.

${ }^{19}$ Notice that ke $P P_{\text {Goal }}$ take scope over the indefinite $D P_{\text {Theme }}$ giving rise to a non-specific reading in the Stative Presupposition.

${ }^{20}$ A reviewer expresses the worry that felicitous examples might be licensed via accommodation of an Eventive Presupposition, rather than the availability of a weaker Stative Presupposition. All our contexts are built in a way that excludes such accommodations, or at least makes them highly improbable. The inadequacy of accommodation as an account of the observed patterns is particularly manifest in cases where the same verbs are judged in exactly the same contexts yet differ in their status. In the case of (65)-(66) one would need to explain why it is possible to accommodate that someone gave a ball to someone other than the boy, but not that someone sold a ball to someone other than the boy in exactly the same context. We have seen plenty of cases of the same type. Notice also that an account based on accommodation wouldn't be able to predict the systematic differences among different sub-classes of result verbs.
} 
(67) Context for Stative presupposition:

Last night in my dream I was walking down an empty road holding a yellow ball. A boy materialized in front of me. He had a red ball in his possession. He told me he wasn't happy with his red ball, so ...

edhosa /\# pulisa sto aghori ke tin KITRINI bala. gave.1SG sold.1SG at.the boy also the yellow ball 'I gave the yellow ball to the boy too.'

Ditransitive verbs, like the verb stelno 'send', are ambiguous between a caused possession and a caused change of location reading. SPs are licensed for both the Goal (10 out of 11 speakers) and Theme arguments (9 out of 11 speakers), as shown in (70) and (72), respectively, for the caused change of location reading. In its caused possession reading stelno 'send' behaves like dhino 'give' above. Other verbs that behave like stelno 'send' are, in our judgment, its synonyms pembo 'send' and apostelo 'send'. The verb taxidhromo 'mail', on the other hand, behaves differently. Association with the Goal argument licenses no SP (2 out of 11 speakers), as shown in (70). Association with the theme argument, as in (72), gives mixed results (5 out of 11 speakers). In our judgment, the verbs klotsao 'kick' and petao 'throw' are also not SP-generating verbs.

(69) Context for Stative presupposition:

With a movement of her wand, Hermione made a bible appear in John's house in Thessaloniki. A few hours later she went to the post-office and ...

estile / \# tahidhromise ke sto EKSOHIKO tu mia vivlo. sent.3SG mailed.3SG also at.the country-house his a bible 'She sent/ mailed a bible to his country-house too.'

(71) Context for Stative presupposition:

Hermione has a modern painting in her living room. She decided she needed to have a painting in her country-house too. With a movement of her wand, she made a classic painting appear in her country-house. A few hours later she went to the post-office and ...

(72) estile / ? tahidhromise ke ton MODERNO pinaka sto sent.3SG mailed.3SG also the modern painting at.the eksoxiko tis.

country-house her

'She sent/ mailed the modern painting to her country-house too.'

In Double Object Constructions (DOCs) the Goal argument appears in Dative Case (morphologically genitive), as in (73). As mentioned above, DOCs only have caused possession readings. We observe no difference between DOCs and POCs in the licensing of SPs; examples with DOCs elicit the same responses as their corresponding POCs in the same contexts. ${ }^{21}$

${ }^{21}$ According to Larson (1990), DOCs exhibit 'scope freezing effects,' so that the theme argument cannot scope over the goal argument, as in (i). This judgment seems to be replicable in Greek DOCs. ke DP Theme too cannot out-scope an indefinite $D P_{\text {Goal }}$ in a stative reading, as in (ii). This is expected in the scopal 


Edhosa ke tu AGHORJU mia bala.
gave.1SG also the.GEN boy.GEN a ball
'I gave a ball to the boy too.'

In summary, we have observed that, even though ditransitive verbs are all associated with two-point scales, i.e., bounded scales, they do not all license SPs. SP licensing is similarly not dependent on the specific interpretation of the verb (caused possession vs. caused change of location), nor is it dependent on the choice of construction (POC vs. DOC) or associate (Theme vs. Goal). Instead, it is dependent on some property of the individual verbs, the most obvious being the presence of a manner component of meaning.

\subsection{In search of a generalization}

Four major observations emerge: (i) Incremental Theme verbs do not give rise to SPs (with the possible exception of some creation verbs), (ii) Degree Achievements always give rise to SPs, (iii) COS verbs, DM verbs, and ditransitives show internal variation, and (iv) manner bleeds SP licensing. A successful analysis of this distribution requires a three-way distinction between IT verbs, DA verbs and the rest. These generalizations are in principle compatible with the classification in Rappaport Hovav (2014) as long as we introduce at least two further distinctions: (i) a distinction between DA and COS verbs, and (ii) a distinction between SP-licensing and non-SPlicensing COS, DM, and ditransitive verbs. In doing so we need to establish whether there exists a single attribute that is predictive of SP-licensing across sub-classes of result verbs. As we have seen above, none of the different ways used in Rappaport Hovav (2014) to distinguish between result verbs predicts SP-licensing.

A distinction that needs more careful consideration is the one between 'simplex' and 'complex' changes. In the classification above we took 'simplex' changes to be changes along a two-point scale and 'complex' changes to be changes along a multi-point scale. This distinction roughly corresponds to the distinction in Ramchand (2008) between 'telic caused processes' (i.e., predicates that express a changeof-state along a property scale) and 'caused results' (i.e., verbs that express an instantaneous transition to an endstate). Ramchand (2008) is one of the very few works that make an explicit proposal about the relation of such a distinction with the syntax of verbal decomposition. According to Ramchand, the syntactic structure of telic caused processes does not include any syntactically expressed state, whereas that of

analysis pursued here. Notice, however, that according to our judgment, there is only a marginal difference between (i)-(ii) and corresponding cases in Greek POCs, where ke $D P_{\text {Theme }}$ can only marginally outscope an indefinite $P P_{\text {Goal }}$. At this point we cannot know what the correct generalization is. A more careful empirical investigation is required. Note also that Bruening (2019) has recently questioned the validity of the original generalization in English based on an experimental investigation.

(i) The woman gave a dog every bone.

(ii)
Edhosa enos aghorju ke tin KUKLA. gave.1SG a.GEN boy.GEN also the doll 'I gave a child the doll too.'

$$
\begin{aligned}
& \exists>\forall / * \forall>\exists \\
& \exists>\text { ke DP / *ke DP> }>
\end{aligned}
$$


caused results does. Given our analysis of SPs, the straightforward prediction under this classification is that all and only caused result verbs will license SPs. We have seen, however, that this prediction fails in both directions. First, there exist telic caused processes/ complex changes that do license SPs, e.g., klino 'close' and steghnono 'dry', but also ones that do not; e.g., katharizo 'clean' and epidhiorthono 'fix'. Second, whereas some caused results/ simplex changes do not give rise to SPs, e.g., spao 'break', others do; e.g., petheno 'die'.

A more promising distinction can be found in the distinction between 'accomplishment verbs based on simple states,' like darken, and 'accomplishments involving derived states,' like break (Embick 2009; based on Koontz-Garboden and Levin 2005) Limiting ourselves to COS verbs, this distinction could be taken to underlie the distinction between SP-generating verbs like anigho 'open', and non-SP-generating verbs like ftiaxno 'fix'. But what does it mean exactly to be a 'simple' or a 'derived' state? Whereas Embick posits a syntactic distinction between the two classes, Koontz-Garboden (2005, 2010), Koontz-Garboden and Beavers (2017), Beavers and Koontz-Garboden $(2012,2017,2020)$ attribute the difference to properties of the encyclopedic component (the 'root'). They distinguish between 'property concept' roots and 'caused result' roots (based on Dixon 1982). According to these works, state denoting roots come in two varieties (i) roots denoting states that can be independently available in the absence of any event leading up to them such as the states of being dark or open, which we will also call 'simple state roots,' and (ii) roots denoting states that can only arise as the result of a previous process such as the states of being broken or fixed, which we will call 'result roots.' Property concept/ simple state roots tend to refer to properties like color, intrinsic physical properties, and qualities. In the languages of the world, they tend to be categorized as adjectives (if a language has that category). Result states tend to be categorized as verbs and have no corresponding simple adjective. The corresponding adjectives are de-verbal and, unlike simple state adjectives, entail an event of change (e.g., red vs. thawed).

In Greek, the vast majority of property concepts can and do form simple adjectives. Their corresponding verbal forms constitute the class of result verbs we called Degree Achievements. What is interesting for current purposes is that some COS verbs also seem to correspond to property concepts. These are COS verbs that license SPs. Take, for example, the verbs anigho 'open' and klino 'close'. There are no simple adjectives in Greek corresponding to these verbs. The corresponding adjectives are derived as -tos participles, as in (74). Crucially, these derived adjectival forms have no eventive entailments; (74) entails no opening/ closing of the door.

$$
\begin{aligned}
& \text { I porta ine anixti/ klisti. } \\
& \text { the door is open.ADJ closed.ADJ } \\
& \text { 'The door is open/ closed.' }
\end{aligned}
$$

COS verbs built on result state roots, on the other hand, either do not form -tos adjectives, as in (75), or receive special or metaphorical readings, as in (76). In no case do the derived adjectives correspond to a simple stative meaning; i.e., a meaning with no eventive entailments.

$$
\begin{aligned}
& * \text { ljotos/ *rajistos/ *lerotos/ ... } \\
& \text { melt.ADJ crack.ADJ dirt.ADJ }
\end{aligned}
$$



spastos
/ ftiaxtos
break.ADJ
fix.ADJ
'that can be separated in pieces' 'artificial'

It seems, then, that we have found an independently motivated distinction that predicts the sub-class of SP licensing verbs among COS verbs. Notice that the claim is not that verbs whose endstates are intuitively simple states are SP-generating verbs; i.e., it is not enough that the endstate that obtains at the end of the event can be described in terms of a simple state. For example, the endstate of the verbs petheno 'die', skotono 'kill', and pnigho 'drown' is the same simple state of being dead, yet only petheno 'die' is a SP-verb. So the licensing of SPs cannot be fully reduced to the presence of a simple state in the root meaning; the presence of a simple stative meaning component is a necessary but not a sufficient property for the licensing of SPs. ${ }^{22}$ The crucial distinction is whether the root meaning contains an eventive component (or more simply a transition to a state) or not. If it does, no SP can be generated.

The explanatory power of appealing to the distinction between property concepts and caused results is limited, however. For one thing, although the distinction is very intuitive, it is difficult to formally define it. In fact, there is no positive definition of property concepts; property concepts are stative meanings that are not result states. Thus, the evidence for the distinction is primarily distributional (see e.g., Beavers et al. 2017 for a cross-linguistic investigation). Also, one cannot attribute the distinction to properties of (our understanding of) the world. Although it is intuitively clear that a state of being open or closed is intuitively a simple state that does not necessarily require some prior event to bring it about, or that the state of being 'broken' (i.e., to be in pieces that used to form a unity) does intuitively require some prior eventuality, it is not immediately obvious why the endstate of a verb like fix should be of the former type. As we saw above, even a case like petheno 'die', where our world knowledge seems to require a transition from being alive to being dead, is linguistically based on a simple state. This is even more striking in the case of DM and ditransitive verbs, where SP-generating and non-SP-generating verbs do not differ in the nature of the endstate associated with the events of change they describe. This is always a simple state of ' $x$ being at/ in/ under/ ... y' in the case of DM verbs and a simple state of possession/ location in the case of ditransitives. We take this to mean that we are dealing with a purely lexical distinction and put aside the question of why different result verbs behave as they do. Whether a predictive theory of the distinction between simple state and result state roots can be formulated is an open question (see Beavers and Koontz-Garboden 2020 for some recent discussion of this issue).

Finally, notice that although the distinction is applicable to COS verbs, it cannot by itself be used to explain the behavior of DA or IT verbs; i.e., one cannot simply say that DA verbs generate SPs because they are built out of simple state roots, whereas IT verbs don't because they are built out of result state roots. First of all, the fact that DA verbs and IT verbs behave uniformly in terms of SP-licensing would be coincidental. ${ }^{23}$ It would also remain mysterious why DA verbs always correspond to

\footnotetext{
${ }^{22}$ As we will argue in Sect. 7.1, this is an important point in arguing against possible non-structural accounts of SPs.

${ }^{23}$ See Sects. 5.3 and 5.7 for some more discussion of this point.
} 
morphologically simple adjectives (which was our initial motivation for treating them as a separate sub-class). Similarly, treating IT verbs in the same way as COS verbs would leave their structural and grammatical differences, as explored in Rappaport Hovav (2014), unexplained. ${ }^{24}$

We conclude that the distribution of SPs minimally requires a three-way distinction between IT-verbs, DA verbs, and the rest. Variation across sub-classes of result verbs in the licensing of SPs should receive a different explanation than sub-classinternal variation. We propose that variation across sub-classes is due to structural differences between the sub-classes. This will require to introduce a further structural distinction between DA and COS verbs in Rappaport Hovav's classification. Variation within sub-classes will be attributed to minimal differences in the meanings of roots. This requires introducing the distinction between simple state and result state roots in the classification. In the next section we propose an account of the distribution of SPs along these lines within the framework of Distributed Morphology.

\section{Stative Presuppositions and the meaning of roots}

We capture the distribution of SPs by appealing to semantic and structural nonuniformity of result verbs. We propose that (i) IT verbs are subject to an incrementality-based analysis, (ii) DA verbs are ambiguous and allow both scalar and an eventdecompositional analyses, and (iii) COS verbs, DM verbs, and ditransitives receive an event decompositional analysis. We attribute these distinctions to the way different types of roots can interact with verbal functional material and other operators. Moreover, treating roots as the locus of encyclopedic information explains both the lexical variation within COS, DM and ditransitive verbs and the effect of manner. Only verbs built out of simple state roots give rise to SPs. In other words, we attribute the inability of IT verbs and the ability of all DA verbs to give rise to SPs to structural reasons, while the split within the remaining classes is attributed to differences in the content of the encyclopedic component of the relevant verbal decompositions. The inability of manner verbs to license SPs will also follow from such differences.

In order to execute this strategy, we need to move to a framework of verbal decomposition that is more explicit about the locus of the distinction between encyclopedic and non-encyclopedic ('templatic,' as it is usually called) meaning and about the syntax of verbal decompositions. As before, there is a number of frameworks that could fit the bill. Here we will assume Distributed Morphology. Distributed Morphology is, indeed, particularly explicit about the distinction between encyclopedic components (the 'root') and non-encyclopedic components (various functional heads in the extended verbal projection) and about the principles that are taken to govern the way they interact. More importantly, Distributed Morphology places the locus of verbal decomposition in syntax proper, which, we have argued and will argue further, is necessary in order to account for Eventive-Stative ambiguities. Notice, finally, that,

\footnotetext{
${ }^{24}$ Notice also that unlike the non-SP-licensing COS verbs in (75), many IT verbs can form -tos adjectives (e.g., plektos 'knitted', xtistos 'built', kentitos 'sewn', a.m.o.). All these derived adjectives denote states that are the result of some previous process. In all cases like the ones discussed in this section -tos has been argued to attach to the root. See Anagnostopoulou and Samioti $(2013,2014)$ for details.
} 
like before, we are mostly interested in presenting the minimum requirements needed to capture the relevant facts about SPs, rather than proposing a definitive analysis of different sub-classes of result verbs.

\subsection{Distributed Morphology}

We begin with presenting the relevant aspects of Distributed Morphology (DM, Halle and Marantz 1993 and much subsequent work). Distributed Morphology is a framework specifically designed around the assumption that word-formation is syntactic. Hence, lexical categories in DM are determined in the syntactic component. The basic ingredients of word-formation are roots, which are taken to be primitive elements that enter the syntactic computation, and a limited set of categorizing functional heads. In the case of verbs, the relevant head is the verbalizer $v$. What the root contributes semantically is the invariant meaning contributed across different syntactic environments. ${ }^{25}$ Properties of event- and argument-structure are taken to be largely determined by properties of the syntactic structure (the verbalizer and other functional material) in which roots are embedded (rather than being properties of individual lexical items). In that fashion, the distinction between encyclopedic and nonencyclopedic meaning is reflected in the distinction between meaning contributed by the root and meaning contributed by functional material.

There are many different analytical possibilities in executing this idea. We present our current assumptions using the example of a COS verb like anigho 'open', in (77). The stative predicate detected by the presence of SPs is provided by the root, as in (78a), whose complement is the internal argument bearing a Theme or Patient role. We assume that next to its function as a verbalizer, $v$ contributes causative semantics, as in (78b). The external argument is introduced by a separate functional head, Voice, and bears the Agent role, as in (78c). We assume with Alexiadou et al. (2006), Schäfer (2008), Alexiadou et al. (2015) a.o. that Voice is the locus of argument structure alternations. ${ }^{26} \mathrm{DM}$ is a realizational framework of morphology. We adopt the standard assumption in DM that the lexical verb spells out the result of head movement of the root to Voice, through $v$. Since this is of no consequence for the point made here, we suppress head movement in our representations.

$$
\begin{aligned}
& \text { [VoiceP DP } \mathrm{DP}_{\mathrm{ext}}\left[\text { Voice } \left[\mathrm{vP} \mathrm{V}_{\mathrm{CAUSE}}[\sqrt{ } \mathrm{P} \sqrt{ } \text { anigh- DP }\right.\right. \\
& \text { int }]]] \\
& \text { a. } \llbracket \sqrt{ } \text { anigh- } \rrbracket=\lambda \mathrm{x}_{\mathrm{e}} \lambda \mathrm{s}_{\mathrm{s}} \cdot \text { open }(\mathrm{x})(\mathrm{s}) \\
& \text { b. } \llbracket \mathrm{V} \rrbracket=\lambda \mathrm{p}_{\mathrm{st}} \lambda \mathrm{e}_{\mathrm{s}} \exists \mathrm{s} \cdot \mathrm{p}(\mathrm{s}) \& \text { e is an event of causing s } \\
& \text { c. } \llbracket \text { Voice } \rrbracket=\lambda \mathrm{p}_{\mathrm{st}} \lambda \mathrm{x}_{\mathrm{e}} \lambda \mathrm{e}_{\mathrm{s}} \cdot \mathrm{p}(\mathrm{e}) \& \text { agent }(\mathrm{x})(\mathrm{e})
\end{aligned}
$$

We assume that roots have all the properties of run-of-the-mill syntactic heads (see Harley 2014); i.e., they can take complements and they project their own phrases (here, $\sqrt{ } P$ ). If, on the other hand, internal arguments can only be licensed after verbalization, as in e.g., Borer (2003, 2009), we would need to dissociate causative se-

\footnotetext{
${ }^{25}$ For discussion of cases in which the meaning of roots is not invariant see Harley (2014).

${ }^{26}$ This predicts that the generation of SPs should not interact with alternations like passivization and anticausativization. As far we have been able to see, the availability of SPs is, indeed, not affected by any alternations.
} 
mantics from the verbalizer $v$. One possibility would be to introduce causative semantics syncategorematically as in Kratzer (2004), Schäfer (2008). ${ }^{27}$ We leave this option open. We have assumed that roots are individuated semantically in the syntactic component. See Harley (2014) and responses to that paper for discussion of an alternative. This issue does not bear on the generation of SPs either.

\subsection{COS verbs}

Following the classification in Rappaport Hovav (2014) we assume that SP-licensing (open-type) and non-SP-licensing (fix-type) verbs are syntactically and semantically uniform and locate the difference between the two sub-types in the semantic contribution of the root. We take it that the roots of COS verbs are either simple state roots, e.g., the root of anigho 'open' in (80) or result state roots, e.g., the root for ftiaxno 'fix' in (79), which describes the state of having been restituted to a working condition. Notice that we refrain from using operators like CAUSE or BECOME in describing the meaning of result state roots, as this might be taken to imply that the relevant parts of the meaning of the root should exhibit all the properties associated with these operators. In fact, we see no reason to a priori assume such a similarity and remain agnostic on this issue. What is crucial for our purposes is that the meaning of a result state root is not a simple state, but includes, at least, a transition to a state. We indicate this by use of the derived adjectival form 'fixed' in the meta-language. ${ }^{28}$

$$
\llbracket \sqrt{ } \text { ftiaxn- } \rrbracket=\lambda x_{e} \lambda s_{s} \text {. fixed(x)(s) }
$$

The generation of SPs for open-type verbs runs in a way exactly parallel to the analysis in Sect. 3.2. SPs are generated when ke DP takes scope in the lowest possible position, here its merging position as a complement of the root. On the other hand, fix-type verbs generate no SPs since even in the lowest scope taking position the argument of ke DP is not a simple state, but a result state.

\subsection{Degree Achievement verbs}

Consider next DA verbs, i.e., verbs whose roots can be used to build morphologically simple adjectives. Recall that all DA verbs are SP-generating verbs. The minimum requirements for the generation of SPs could lead us to assume that the decomposition of DA verbs is also based on simple state roots, as in (80) for stegnono 'dry' and akriveno 'become expensive'.

\footnotetext{
${ }^{27}$ In such a set-up one would expect the availability of SPs to interact with the 'bundling parameter' (Pylkkänen 2002/2008); i.e., the proposal that languages differ in whether the functions of Voice and $v$ are unified in a single head or not.

${ }^{28}$ Alternatively, one could assume that result state roots denote predicates of events, as in (i). In that case they would need to be integrated into the structure a different way, perhaps as modifiers of $v$. See also Sect. 5.6 for related discussion. This, however, would imply more structural differences between fix- and open-type verbs than justified by Rappaport Hovav's classification. We provide more evidence against such a distinction in Sect. 6. Some additional evidence that fix-type verbs should be treated as predicates of states comes from the licensing of result state reading of for-phrases, as discussed in Sect. 7.4.
}$$
\llbracket \sqrt{ } \text { ftiaxn- } \rrbracket=\lambda x_{\mathrm{e}} \lambda \mathrm{e}_{\mathrm{s}} \text {. fixed(x)(e) }
$$ 


$$
\begin{array}{ll}
\text { a. } & \llbracket \sqrt{ } \text { stegn- } \rrbracket=\lambda x \lambda \text { s. } \operatorname{dry}(\mathrm{x})(\mathrm{s}) \\
\text { b. } & \llbracket \sqrt{ } \text { akriv- } \rrbracket=\lambda \mathrm{x} \lambda \mathrm{s} . \operatorname{expensive}(\mathrm{x})(\mathrm{s})
\end{array}
$$

We mentioned some reasons why such a unification is undesirable in Sect. 4.5. Moreover, an account that builds DA verbs solely on the basis of simple state roots runs in the face of a significant body of literature that has demonstrated the necessity of a degree-based scalar analysis. Since scalar analyses do not contain a stative constituent in their syntactic decomposition and cannot predict the generation of SPs, we are forced, at the very least, to assume an ambiguity account of such verbs (contra Kennedy and Levin 2008; Pedersen 2014, a.o.). For example, von Stechow (1996) proposes that Degree Achievements are built based on either the positive or the comparative form of the corresponding adjective (see also Abusch 1986). There are a number of known problems with such ambiguity accounts, as discussed especially in Kennedy and Levin (2008) and Pedersen (2014). Spathas (2019) proposes a reinterpretation of an ambiguity account that places the ambiguity on properties of the verbalizer, rather than an underlying adjectival structure. The relevant roots are always interpreted as measure functions; i.e., functions from individuals to degrees relativized to eventualities (cf. Kennedy and Levin 2008), as in (81). ${ }^{29}$

$$
\begin{array}{ll}
\text { a. } & \llbracket \sqrt{ } \text { steghn- } \rrbracket=\lambda \times \lambda i \text { i. dryness (x)(i) } \\
\text { b. } \llbracket \sqrt{ } \text { akriv- } \rrbracket=\lambda \times \lambda i \text {. price }(\mathrm{x})(\mathrm{i})
\end{array}
$$

These are the same roots used in the construction of the corresponding adjectives. Notice that the meanings in (81) are not properties of individuals. They are turned into such after application of a POS operator (Kennedy 2007) that locates the degree that the measure function returns relative to a contextual standard, as in (82).

$$
\begin{array}{ll}
\text { a. } & \llbracket \text { POS } \sqrt{ } \text { steghn- } \rrbracket=\lambda x \lambda \text { s. dryness }(\mathrm{x})(\mathrm{e}) \geq \text { standard(dryness) } \\
\text { b. } & \llbracket \text { POS } \sqrt{ } \text { akriv- } \rrbracket=\lambda x \lambda \text { s. price }(\mathrm{x})(\mathrm{s}) \geq \text { standard(price) }
\end{array}
$$

Crucially, these are now stative predicates which can be complements of verbalizers $\left(v_{C A U S E}\right.$ or $v_{B E C O M E}$ ), just like stative roots in the previous section, as in (83). Assuming, as seems natural, that the internal argument is an argument of this constituent, it is also of the right type to compose with ke DP. Such a derivation can thus give rise to SPs. The required presuppositions are generated under the familiar assumption of degree-based analyses of gradable adjectives that the standard is determined by properties of the underlying scales; in the case of a scale with a maximum degree, as in (83a), the standard is equated with the maximum, whereas in the scale of an open scale, as in (83b), the standard is context dependent.

$$
\begin{array}{ll}
\text { a. } & {\left[\ldots\left[\mathrm{vP}_{\mathrm{CAUSE}} / \mathrm{BECOME}\left[\sqrt{ } \mathrm{P}[\mathrm{POS} \sqrt{ } \mathrm{steghn}] \mathrm{DP}_{\text {int }}\right]\right]\right]} \\
\text { b. } & {\left[\ldots\left[\mathrm{vP} \mathrm{v}_{\mathrm{CAUSE} / \mathrm{BECOME}}\left[\sqrt{ } \mathrm{P}[\mathrm{POS} \sqrt{ } \text { akriv- }] \mathrm{DP}_{\text {int }}\right]\right]\right]}
\end{array}
$$

\footnotetext{
${ }^{29}$ Beavers and Koontz-Garboden (2020) propose an analysis of Degree Achievements that brings together a degree-based semantics with stative roots, without treating them as strictly deadjectival. We cannot exclude such an alternative here. We will stick to an approach that treats the relevant roots as measure functions, however, as it gives a straightforward account of the absence of class internal variation in the licensing of SPs.
} 
Alternatively, the roots in (81) can be directly verbalized by a verbalizer $v_{C O M P}$, which leads to a 'comparative'/ 'scalar' reading, as in standard scalar analyses of such predicates, such as Kennedy and Levin (2008) or Pedersen (2014). Allowing derivations like (83b) for relative Degree Achievements is a contentious issue in the literature. Kearns (2007) and McNally (2017) have already argued that an account along the lines of Kennedy and Levin (2008) is too restrictive for relative DAs, however. In a preliminary investigation with 8 Greek speakers, it seems, indeed, that they readily accept evaluativity inferences (i.e., inferences to the positive degree) and telic readings for relative DAs in the presence of an explicit contextual standard. ${ }^{30}$ In the absence of an explicit standard, speakers clearly favor a scalar interpretation. The suggestion here is that evaluativity inferences and telic readings need not only depend on the choice of standard (as usually assumed in scalar analyses of DAs), but might also have a structural source, the derivations in (83). An important question under such an ambiguity approach is what determines the preference for a scalar derivation in out-of-the-blue contexts. Spathas (2019) suggests that this is because scalar derivations are based on a trivial standard-of-change, the degree in the relevant property at the beginning of the event, so that no information other than what is provided by the predication itself is required to determine this standard. It is natural to assume, then, that in the absence of relevant information speakers will choose the derivation using a trivial standard-of-change rather than inventing a contextual standard.

It would take us too far afield to provide a full exposition of the scalar analysis or to defend the particular version of the ambiguity account we are alluding to here. We refer to Spathas (2019) for more detailed discussion, additional evidence in favor of an ambiguity account and comparison with alternatives. The crucial point for us here is that constituents of the type in (82) are independently needed in degree-based accounts of gradable adjectives. ${ }^{31}$ If so, the existence of derivations that verbalize such constituents is unsurprising. The fact that all DA verbs are SP-generating verbs is what one naturally expects.

\subsection{DM verbs}

Greek fails to license directed motion readings with manner of motion verbs. On the basis of this fact it has been argued that a preposition such as Greek se does not contribute Path (Terzi 2010a, 2010b; a.o.) and that Path is lexicalized as part of the verb meaning in the case of Directed Motion verbs (Gehrke and Lekakou 2013); i.e., the verbs which do allow for a Prepositional Phrase to specify the Goal or final location of the dynamic event. Although we retain the first of these conclusions, the analysis of SPs forces us to drop the second one, at least for the case of those DM

\footnotetext{
${ }^{30}$ The licensing of restitutive presuppositions of ksana 'again' with relative Degree Achievements also points to the same conclusion (Spathas 2019). See Beavers and Koontz-Garboden (2020:42-43) and Pedersen (2014) for similar facts in English and discussion of different ways to approach them. This discussion is complicated by the potential availability of counter-directional readings of repetitive modifiers.

${ }^{31}$ Given the necessity of (82) for the analysis of gradable adjectives, degree-based accounts that only allow 'comparative' readings of DAs can only block derivations like (83) by stipulation. As far we know, this issue is not discussed in the relevant literature, not even in works that want to exclude such 'positive' verbal derivations.
} 
verbs that license SPs. In order to conform with the minimal requirements for an analysis of SPs we assume that (i) the roots of upper-bounded DM verbs are stative roots which lexicalize a location, and differ on whether they include any information about transition to a final location, (ii) the subject is merged as an argument of the root, and (iii) the PP is necessarily in the scope of the subject; i.e., it is either an argument of the root or an adjunct attached on the root. We assume the former.

We first demonstrate with a verb that gives rise to SPs, beno 'enter'. The root benis a stative root with roughly the meaning in (85). It takes two arguments, the first of which specifies a location and the second a theme. For simplicity, we assume that the preposition se is semantically vacuous. ${ }^{32} \mathrm{~A} k e$ DP introduced as the theme argument takes scope above the root and the PP giving rise to a SP, as required. All eventive and dynamic properties of the predication are contributed by functional material, here a $v_{B E C O M E}$ verbalizer with the informal meaning in (86) (von Stechow 1996; Beck and Johnson 2004). ${ }^{33}$

$$
\begin{aligned}
& {\left[\mathrm{vP}_{\mathrm{BECOME}}\left[\sqrt{ } \mathrm{P} D \mathrm{DP}_{\text {Theme }}\left[\sqrt{ } \text { ben- } \mathrm{PP}_{\text {Location }}\right]\right]\right]} \\
& \llbracket \sqrt{ } \text { ben- } \rrbracket=\lambda \mathrm{x} \lambda \mathrm{y} \lambda \mathrm{s} \text {. be-in }(\mathrm{x})(\mathrm{y})(\mathrm{s}) \\
& \llbracket \mathrm{v}_{\mathrm{BECOME}} \rrbracket=\lambda \mathrm{p}_{\mathrm{st}} \lambda \mathrm{e}_{\mathrm{s}} \exists \mathrm{s} \text {. e is the smallest event s.t. } \mathrm{p}(\mathrm{s}) \text { does not hold at the } \\
& \text { pre-state of e and } \mathrm{p}(\mathrm{s}) \text { does hold at the target state of e }
\end{aligned}
$$

We now turn to the verb ftano 'arrive' which is in the same sub-class of DM verbs, but does not give rise to SPs, at least for a majority of speakers. We propose that the only difference between the two verbs is in the content of the root meaning; i.e., whereas ben- is a simple state root, the root ftan- is a result state root, as in (87). No SP can be generated since the argument of ke $D P_{\text {Theme }}$ in its lowest scope position necessarily includes a transition to a state.

$$
\llbracket \sqrt{ } \text { ftan- } \rrbracket=\lambda x \lambda y \lambda \text { s. come-to-be-at }(x)(y)(s)
$$

For the limited number of cases of manner of motion verbs that can express directed motion, which are also not SP-generating verbs, we assume that we are dealing with eventive roots that can be coerced into stative roots with a manner component, as in (88) for treho 'run'.

$$
\llbracket \sqrt{ } \text { trex- } \rrbracket=\lambda x \lambda y \lambda \text { s. come-to-be-at-by-running }(\mathrm{x})(\mathrm{y})(\mathrm{s})
$$

\footnotetext{
${ }^{32}$ Alternatively, we could assume that se contributes a bleached, unspecified locative meaning (in the spirit of Terzi 2010b). This would require us to introduce a more precise semantics for locative elements, as in Zwarts and Winter (2000), Zwarts (2005), a.o. Although we believe that an adequate analysis of DM verbs should incorporate some version of such a vector-based semantics, it is not strictly necessary for current purposes and we will refrain from providing one. Notice that, as was the case with degrees in the analysis of Degree Achievements, introduction of vectors does not in and of itself exclude an event-decompositional derivation of DM verbs.

${ }^{33}$ See Gehrke (2008) for independent arguments that directional meanings with locative prepositions are derived structurally. Gehrke proposes a complex-predicate analysis in the spirit of Rothstein (2004), which, however, does not predict the licensing of SPs by DM verbs. See Sect. 6 for more relevant discussion.
} 


\subsection{Ditransitives}

SP-generating ditransitive verbs are such regardless of frame (POC or DOC) or thematic role (association with the Goal or Theme argument). In accordance with the minimal requirements for the generation of SPs, we take this to mean that both POCs and DOCs include in their decomposition a syntactically accessible stative predicate that both internal arguments can take scope over. In the majority of existing work, however, the root (or verb, depending on the details of the analysis) is usually taken to provide an eventive, manner component. We propose, instead, that the root (rather than some type of Small Clause constituent or Applicative head) provides the necessary stative component in Greek ditransitives. This innovation allows us to treat non-SP-ditransitives in exactly the same way as COS and DM verbs; i.e., by replicating the distinction between simple and result/ manner roots.

This basic analytical requirement can be implemented within both derivational and non-derivational analyses of the dative alternation. In derivational analyses (Baker 1988/1997; Larson 1988; Ormazabal and Romero 2010; a.m.o.) DOCs and POCs are argued to have a uniform syntax and semantics, at least as far as the syntactic level that determines argument and event structure is concerned ( $v P$, VoiceP, 'first-phase' syntax, depending on specific analyses). Any differences between the two are taken to be epiphenomenal, usually due to movement or incorporation of a preposition to positions higher up in the structure. Non-derivational analyses, on the other hand, assume syntactic and semantic differences at all levels between DOCs and POCs (Oehrle 1976; Green 1974; see also Harley and Miyagawa 2017 for a general overview). Non-derivational analyses are divided between symmetric analyses, according to which DOCs and POCs have the same structure but differ in the content of a Small Clause constituent and the order of internal arguments (Harley 1997, 2002; Pesetsky 1996; Lascaratou and Georgiafentis 2003 for Greek). Asymmetric analyses, on the other hand, assume that arguments are integrated and/ or introduced differently in the two cases; whereas both arguments are arguments of the verb in POCs, Goals are arguments of functional heads in DOCs (Marantz 1993; Bruening 2001, 2010; Anagnostopoulou 2003 for Greek). Our approach can also be implemented within symmetric and asymmetric analyses. In what follows we provide some sample derivations, adapted to our basic assumption that the roots of ditransitive verbs are stative constituents. Our main concern is to provide an analysis that captures the generation of SPs in a way consistent with the framework adopted in the rest of the paper. It is beyond the scope of this paper to decide between the major approaches to the dative alternation or provide an analysis that captures all known similarities and differences between POCs and DOCs. The relevant issues are simply too many and the relevant literature too vast to do justice to here. Such an endeavor is left for future work.

We start with Prepositional Object constructions. We assume that the root takes two arguments, a PP introducing the Goal and a DP introducing the Theme, as in (89), with the former being asymmetrically c-commanded by the latter, as indicated by Barss and Lasnik's (1986) c-command diagnostics (as applied to Greek ditransitives by Anagnostopoulou 2003 and Michelioudakis 2012). For simplicity, we take the preposition $s(e)$ to be semantically vacuous. The root of a ditransitive verb expressing 
caused possession, such as dhino 'give', contributes a state of possession, as in (90). ${ }^{34}$ In the case of association with the Theme argument, ke DP can be interpreted in its merge position giving rise to a SP according to which some alternative to the Theme is in the possession of the Goal.

$$
\begin{aligned}
& \text { [VoiceP DP } \left.\left.\text { ext }_{\text {[ Voice }\left[{ }_{\mathrm{vP}} \mathrm{v}_{\text {CAUSE }}[\sqrt{ } \mathrm{P} \text { ke DP }\right.} \text { Theme }\left[\sqrt{ } \text { dhin- } \mathrm{PP}_{\mathrm{Goal}}\right]\right]\right] \\
& \llbracket \sqrt{ } \text { dhin- } \rrbracket=\lambda x \lambda y \lambda s . \operatorname{POSS}(y)(x)(s)
\end{aligned}
$$

In the case of association with the Goal argument, there is a type mismatch between ke DP and the root. This is resolved by $\mathrm{QR}$ to a propositional node. Short $\mathrm{QR}$ to the first available propositional node, $\sqrt{ } P$ in (89), gives rise to a SP according to which some alternative to the Goal possesses the Theme. Notice that ke PP $P_{\text {Goal }}$ takes scope over the Theme argument, predicting correctly that indefinite themes can give rise to non-specific readings, as observed in Sect. 4.4.

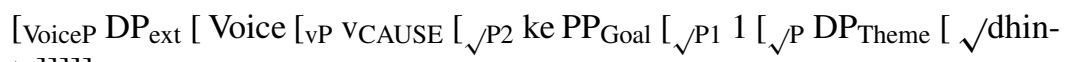
$\left.\left.\left.\mathrm{t}_{1}\right][]\right]\right]$

$$
\llbracket \sqrt{ } \mathrm{P} 1 \rrbracket=\lambda \mathrm{y} \lambda \mathrm{s} . \operatorname{POSS}(\mathrm{y})\left(\llbracket \mathrm{DP}_{\text {Theme }} \rrbracket\right)(\mathrm{s})
$$

For verbs ambiguous between caused possession and caused change of location we locate the ambiguity in the root, as in (93) for the SP-generating verb stelno 'send'. The generation of SPs proceeds exactly as above.

$$
\begin{array}{ll}
\text { a. } & \llbracket \sqrt{ } \text { stel- } \rrbracket=\lambda x \lambda y \lambda s . \operatorname{POSS}(y)(x)(s) \\
\text { b. } & \llbracket \sqrt{ } \text { stel- } \rrbracket=\lambda x \lambda y \lambda s . \operatorname{BE}-\operatorname{AT}(y)(x)(s)
\end{array}
$$

Consider next Dative Object Constructions, where the Goal argument bears dative case (morphologically genitive in Greek). ${ }^{35}$ The generation of SPs for DOCs is largely similar. In a derivational approach there is no need to add anything more. The generation of SPs proceeds in exactly the same way as with POCs above. Movement of $D P_{\text {Goal }}$ (Larson 1988) or incorporation of the preposition (as in Baker 1988/1997) to higher nodes does not affect the scopal properties of the internal arguments. In

\footnotetext{
${ }^{34}$ As a reviewer points out this treatment raises non-trivial questions about how to differentiate between SP-licensing verbs like dhino 'give', paradhino 'deliver/ hand in', pernó 'pass' and paraxoro 'cede $\mathrm{x}$ to $y$ ', if their roots all denote the same possessive relation. It seems clear that the verbs differ in the content of some process component. To deal with these cases within the framework we have adopted here, we could consider the possibility that these verbs are built out of two roots (one of which is possibly null, without an overt exponent), a simple state root which introduces the internal argument, and an eventive root that modifies $v$ and gives content to the process component. This approach goes against the proposal in Rappaport Hovav and Levin (2010) that verbs are built out of single roots (see also the discussion of Folli and Harley 2005 in Sect. 6). It also becomes less clear how to differentiate these verbs from manner+result verbs, if the latter actually do exist.

${ }^{35}$ Despite variability with respect to the surface order of the two arguments in Greek DOCs, whereby themes may precede goals and vice-versa, the application of standard asymmetric c-command diagnostics (Barss and Lasnik 1986) indicates that $D P_{\text {Goal }}$ must be invariably structurally higher than $D P_{\text {Theme }}$ (see Anagnostopoulou 2003; Lascaratou and Georgiafentis 2003; Michelioudakis 2012). Anagnostopoulou (2003) analyses $D P_{\text {Theme }}-D P_{\text {Goal }}$ orders as the result of $\mathrm{A}^{\prime}$-scrambling of $D P_{\text {Theme }}$, which cannot reverse binding and scope relationships.
} 
the derivational approach of Greek DOCs in Michelioudakis (2012) in (94), DP Goal moves to an Appl head, where it receives dative case.

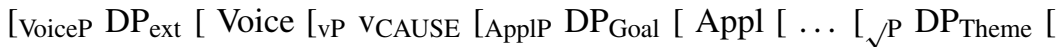
$\sqrt{ }$ dhin- tGoal $_{\text {end]]]]] }}$

In non-derivational approaches things are slightly different, since the order of internal arguments is different than in POCs. In a symmetric approach to the dative alternation we can assume a derivation, as in (95) for dhino 'give'. As in the case of POCs, the root is taken to contribute a stative component and to take two arguments, both DPs. Dative case is licensed by movement of $D P_{\text {Goal }}$ to the specifier of a higher functional head, here marked as Appl(icative) (see Georgala 2012 for Greek). ${ }^{36}$ Restriction to caused possession in DOCs should also be attributed to properties of this head. The generation of SPs proceeds as above, under the assumption that $D P_{\text {Goal }}$ can be interpreted in its merge position.

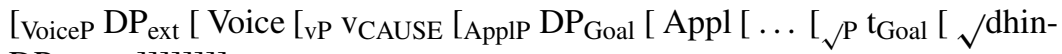
$\left.\left.\left.\left.\mathrm{DP}_{\text {Theme }}[]_{]}\right]\right]\right]\right]$

$$
\llbracket \sqrt{ } \text { dhin- } \rrbracket=\lambda x \lambda y \lambda s . \operatorname{POSS}(\mathrm{y})(\mathrm{x})(\mathrm{s})
$$

In an asymmetric approach to the dative alternation, we can assume that the possessor is introduced by a functional head, e.g., an Applicative head, as in (97). Restriction to caused possession is explained by the meaning of $\mathrm{Appl}$. In the case of association with the Goal argument, ke DP can be interpreted in its merge position giving rise to a SP. Notice also that in both (95) and (97) (as well as in a derivational approach) $D P_{\text {Goal }}$ will out-scope an indefinite $D P_{\text {Theme }}$, as required.

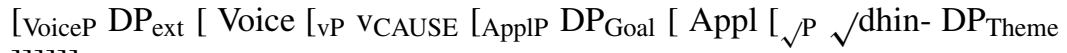
]]]]]]

a. $\quad \llbracket \sqrt{ }$ dhin- $\rrbracket=\lambda x \lambda s . \operatorname{POSS}(\mathrm{x})(\mathrm{s})$

b. $\llbracket$ Appl $\rrbracket=\lambda \mathrm{p}_{\mathrm{st}} \lambda \mathrm{x}_{\mathrm{e}} \lambda \mathrm{e}_{\mathrm{s}} \cdot \mathrm{p}(\mathrm{e}) \& \operatorname{possessor}(\mathrm{x})(\mathrm{e})$

In the case of association with the Theme argument, $\mathrm{QR}$ is required to solve a type mismatch. In the symmetric approach in (99a) the first appropriate landing site is $\sqrt{ } P$. In the asymmetric approach in (99b) the first appropriate landing site is ApplP. In each case a $\mathrm{SP}$ is generated, as required. ${ }^{37}$

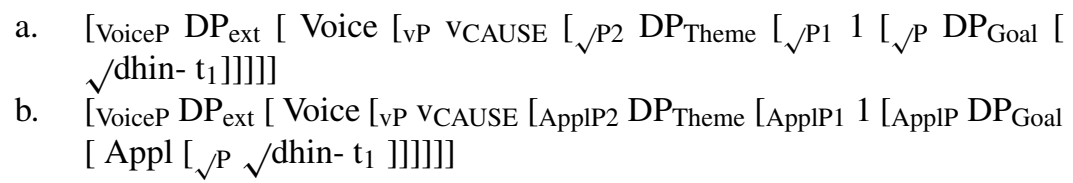

\footnotetext{
${ }^{36}$ Notice that $A p p l$ here introduces a single argument, rather than both internal arguments, as in Pylkkänen's (2002/2008) analysis of Low Applicative heads. For our purposes, Pylkkänen's analysis counts as a Small Clause analysis. See Sect. 6 for discussion.

${ }^{37}$ Approaches differ in how they can in principle handle 'scope freezing effects.' We will not review the relevant literature here, since, as mentioned in fn. 21 above, we are not at the moment sure what is the correct generalization for Greek.
} 


\subsection{Manner verbs}

We have seen that no manner verbs are SP-generating verbs. We propose to derive this fact by assuming that no manner verb can be built on the basis of a simple state root. There are at least two ways to spell this out within current assumptions. The choice depends on one's attitude towards Manner/ Result Complementarity. Rappaport Hovav and Levin (2010) propose a restriction on the decomposition of verbal predicates according to which a verbal root can never simultaneously convey both manner and result entailments. The relevant notion of 'result' for Levin and Rappaport Hovav (2014) is that in the definition of 'result verbs' mentioned above in Sect. 4; i.e., verbs of scalar change. Manner is defined as non-scalar change. Together with a restriction that there can only be one root per sub-event and no more than one root per verb, Manner/ Result Complementarity entails that no verb which supports manner entailments also supports result entailments. In the syntactic decompositional framework assumed here, this amounts to saying that we were wrong to include manner verbs in the investigation of result verbs in Sect. 4 and that manner roots can only be eventive roots with no stative component, as in (100) for pnigho 'drown', where the root simply describes the process of blocking someone's access to oxygen by submerging them into a liquid, here abbreviated as 'drown,' without any reference to a result state of dying (Rappaport Hovav 2018).

$$
\llbracket \sqrt{ } \text { pnigh- } \rrbracket=\lambda \text { e. } \operatorname{drown}(\mathrm{e})
$$

In Distributed Morphology eventive roots are integrated into the structure as modifiers of a process verbalizer $v$, as in (101) (Embick 2009; Harley 2005). Internal arguments are sisters to this complex head, rather than the root. Since no stative constituent is present in this decomposition, no SP can ever be generated.

$$
\left[\ldots\left[\mathrm{vP}[\mathrm{v} \text { VPROC } \sqrt{ } \text { pnigh- }] \mathrm{DP}_{\text {int }}\right]\right]
$$

The issue of Manner/ Result Complementarity is investigated in detail in Beavers and Koontz-Garboden $(2012,2017,2020)$. These works develop a number of tests to diagnose manner and result and argue that manner+result verbs actually do exist. This is what we have been assuming in Sect. 4, since all verbs that we characterized as manner verbs there pass both the manner and result diagnostics of Beavers and Koontz-Garboden $(2012,2017,2020)$. Assuming, as we have done so far, that result entailments in a verb-framed language like Greek are never provided by a templatic/ Small Clause constituent, it follows that both manner and result entailments stem from the meaning of the root. Manner+result roots, then, are result state roots with a modified eventive component, as in (103) for pnigho 'drown'. Given the decomposition in (102), no SP is generated since no simple state root is present.

$$
\begin{aligned}
& {\left[\text { VoiceP } \mathrm{DP}_{\mathrm{ext}}\left[\text { Voice }\left[\mathrm{vP} \mathrm{V}_{\text {CAUSE }}[\sqrt{ } \mathrm{P} \sqrt{ } \text { pnigh- DP }]\right]\right]\right.} \\
& \llbracket \sqrt{ } \text { pnigh- } \rrbracket=\lambda \mathrm{x} \lambda \mathrm{s} \text {. dead-by-drowning }(\mathrm{x})(\mathrm{s})
\end{aligned}
$$

Alternatively, manner+result roots could denote predicates of events, as in (105), which are integrated in the structure as modifiers of a process $v$, as in (104). Again, no $\mathrm{SP}$ can be generated. The choice depends on whether there are independent arguments in favor of (102) or (104). We leave the choice open here. 


\subsection{Incremental Theme verbs}

Finally, we turn to IT verbs, which don't give rise to SPs, with the possible exception of some creation verbs. In accordance with the classification of result verbs we adopted in Sect. 4 and the arguments in Rappaport Hovav (2014) and Rappaport Hovav and Levin (2010) that the roots of IT verbs are simple eventive roots with a manner component, we assume that IT verbs don't give rise to SPs due to structural reasons. Mereological analyses of IT verbs include no stative component and are, therefore, adequate to predict the pattern. For analyses that treat the roots of IT verbs as simple predicates of events, as in (106) troo 'eat' and skarfalono 'climb', and derive scalar structure based on the part structure of the nominal by use of additional relational operators, see Bochnak (2010), Kennedy (2012).

$$
\begin{array}{ll}
\text { a. } & \llbracket \sqrt{ } \text { tro- } \rrbracket=\lambda x \lambda \text { e. eat }(\mathrm{x})(\mathrm{e}) \\
\text { b. } & \llbracket \sqrt{ } \text { skarfalon- } \rrbracket=\lambda \times \lambda \text { e. } \operatorname{climb}(\mathrm{x})(\mathrm{e})
\end{array}
$$

Alternatively, we could assume that IT verbs are built out of result state roots. This would also predict no SP-licensing. As a reviewer suggests, to account for systematic structural differences between IT verbs and COS verbs, one could assume that the roots of IT verbs are integrated as modifiers of $v$ rather than complements of causative or inchoative $v$ heads. It remains to be seen whether such an analysis can be made compatible with the results of Rappaport Hovav (2014) and the discussion in Sect. 4.5. We cannot decide this issue here. ${ }^{38}$

A remaining open issue regards the special case of creation verbs like pleko 'knit'. These have all the hallmarks of IT verbs and, in addition, seem to include a manner component. Yet they do give rise to SPs for a majority of speakers. We do not have a solution to this puzzle. An obvious candidate would be to adopt a Small Clause analysis that employs a stative predicate EXIST or BE in the decomposition (Dowty 1979; Beck and Johnson 2004; Dobler 2008; a.o.). This, however, would contradict our current strategy of avoiding Small Clauses and run against the concrete arguments against Small Clauses we provide in the next section. At the moment we can only allude to known differences between creation verbs and other IT verbs, since, unlike other IT verbs where the existence of the referent of the direct object is independent of the event itself, creation verbs denote the coming into being of an entity. Some authors (von Stechow 2001b; McCready 2003a; McCready 2003b; Piñón 2006) suggest that at least some arguments of creation verbs are of property rather than individual type. It remains to be seen whether such an approach can be combined with the current analysis of the additive operator in a way that allows the generation of SPs.

\footnotetext{
${ }^{38}$ A causative bi-eventive analysis of IT verbs is suggested in Dowty (1979) and Parsons (1990), who pursue unified analyses of accomplishment predicates. There is no explicit proposal of what the relevant stative predicate would be. See also Beavers (2011b). Rothstein (2004) proposes a causative bi-eventive analysis, but one that does not include a stative component. Higginbotham (2000) proposes a processbased bi-eventive analysis, which includes a stative component. See Levin (2000) and references there for arguments against a causative analysis of creation verbs. We thank Fabienne Martin (p.c.) for discussion of these issues and pointers to the relevant literature.
} 


\subsection{A note on inter-speaker variation}

Our account explains differences between IT verbs, DA verbs, and the rest in the licensing of SPs by appealing to structural differences between the classes and explains intra-class variation by appealing to differences in the content of roots. In this section we suggest that these basic distinctions are also largely supported by the patterns of inter-speaker variation that we have found in our data. Although the number of speakers we have consulted is not large enough to draw any definitive conclusions, some patterns do emerge. First of all, we have found no speaker that treats all verbs alike in terms of SP-licensing. This is also the case for verbs within the classes of COS verbs, DM verbs, and ditransitive verbs. All speakers are thus sensitive to the distinction between SP-licensing and non-SP-licensing verbs and the causes of such a distinction, whether they are structural or not.

More crucially for our specific claims, we observe differences in the degree of inter-speaker variation observed within different classes. Consider first COS verbs, DM verbs and ditransitives. Although there are very clear cases for which all or almost all speakers agree (e.g., klino 'close', epidhiorthono 'repair', beno 'enter', pefto 'fall', dhino 'give', a.o.), we observe variation for others. For example, whereas a clear majority (8 speakers) treats the verb petheno 'die' as a SP-licensing verb, a minority of 3 speakers doesn't. The exact opposite pattern is found for skotono 'kill', which is rejected as a SP-verb by 8 speakers. Other verbs, like liono 'melt', ftano 'arrive', and pijeno 'go' show even more variation, as they are treated as SP-verbs by 5, 5, and 6 speakers, respectively. At the same time, all verbs with manner properties in these classes, show no variation; no speaker treats manner verbs as SP-verbs. ${ }^{39} \mathrm{We}$ claim that the observed degree of inter-speaker variation within these classes should not be surprising under our assumptions. The licensing of SPs in this case depends on fine-grained differences in the encyclopedic content of lexical items, the roots. It is generally possible that speakers can minimally differ in the exact content they assign to listed items. This is even more plausible in the case at hand, since in all relevant cases, the crucial factor is whether an eventive component (or perhaps simply a transition) is present at the root level or not, a meaning component that is also provided by functional material outside the root. It might be the case, then, that for some verbs speakers (i.e., learners) come to different conclusions on whether there is enough evidence to replicate these meanings in the roots or not. ${ }^{40,41}$ At the same time, no variation is expected for manner verbs, if, as suggested above, manner has to be part of the root meaning in manner+result verbs and manner requires eventivity.

Moving to DA verbs, we observe no inter-speaker variation. This, again, is expected if all DA verbs are built out of roots denoting measure functions. The least clear class is the one of IT verbs. Out of three verbs, one is never treated as a SP-verb

\footnotetext{
${ }^{39}$ The only exception appears to be the verb tahidhromo 'mail', but only in the case of association with the goal argument.

${ }^{40}$ In that respect, the Bifurcation Thesis (see fn. 45), which has to be rejected as a strict grammatical principle, could be seen as a possible heuristic guiding the acquisition of the meaning of listed items. We cannot explore such speculations further here.

${ }^{41}$ See Beavers and Koontz-Garboden (2020:71-73) for more discussion on possible reasons for interspeaker variation in the meaning of result verbs.
} 
(skarfalono 'climb'), one is treated as a SP-verb by 3 out of 11 speakers (troo 'eat') and one by 7 out of 11 speakers (pleko 'knit'). Recall that in the case of the creation verb pleko 'knit' speakers also expressed large degrees of uncertainty about their judgments. Our account predicts that these verbs should never be treated as SP-verbs, since they are eventive verbs with no stative component. We do not have a clear idea about how to account for this discrepancy at the moment.

\subsection{Section summary}

We provided an analysis that differentiates between structural and non-structural sources of variation in the generation of SPs. In doing so, we accounted for variation within COS, DM, and ditransitive verbs providing a syntactically and semantically uniform event-decompositional analysis of both SP-generating and non-SPgenerating verbs and placing the relevant difference in the meanings of the roots. The behavior of other classes is attributed to structural differences, following the classification of Rappaport Hovav (2014) and the observed patterns of SP-licensing. We explained the generation of SPs by all DA verbs by assuming a degree-based analysis and the unavailability of SP for IT verbs by alluding to incrementality- or scalarbased analyses and provided the basics of an implementation within the root-based decompositional framework of argument and event structure assumed here. In doing so, we have argued that there should minimally exist a four-way distinction between (i) simple state roots, (ii) result state roots, (iii) eventive roots (with or without result entailments), and (iv) roots denoting measure functions. SPs can only arise if ke DP can take scope over a constituent denoting a simple state. This can only be the case with COS, DM and ditransitive verbs built of simple state roots and DAs under an event-decompositional derivation. In all other cases, no SPs arise since ke DP cannot take scope over such a constituent either because the relevant roots are result state roots integrated in the structure as arguments of $v$ or because they are eventive roots integrated in the structure as modifiers of $v$.

\section{On syntactic alternatives}

This section provides additional evidence against a non-uniform analysis of SPgenerating and non-SP-generating COS, DM, and ditransitive verbs. We do so by focusing on alternatives that do meet the initial requirements of SP-licensing, but differ from the account defended in the previous section in that they allow the stative component to be provided by the 'templatic' component of verbal decomposition (rather than being necessarily associated with the root). We call such analyses Small Clause analyses (SC-analyses). SC-analyses have mostly been deployed in the analysis of ditransitive and DM verbs, as in (107) and (108). The indicated structures can generate SPs as long as (i) the predicate of the SC in (107) denotes a simple state, usually possession or location, and (ii) $\mathrm{DP}_{\text {Theme }}$ in (108) is an argument of a locative Place head, rather than of Path. ${ }^{42}$ In its simplest form the analysis over-generates SPs, since it makes no distinction between SP-generating and non-SP-generating verbs.

${ }^{42}$ Analyses differ in whether Path is taken to be part of the root meaning or the templatic component. More on this below. 


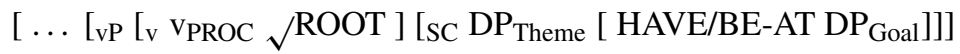

$$
\begin{aligned}
& {\left[\ldots \text { [vP }_{\text {v }} \text { VPROC } \sqrt{ } \text { ROOT ] [(PathP) }(\text { Path) [PlaceP DP Theme [ Place }\right.} \\
& \text { (DP } \left.\left.\left.\left.{ }_{\text {Ground }}\right)\right]\right]\right]
\end{aligned}
$$

We consider some ways to make such a distinction within SC-analyses. Specifically, we consider Embick (2009), whose account is specifically tailored to derive the difference between 'accomplishment verbs based on simple states' and 'accomplishments involving derived states'. ${ }^{43}$ The distinction corresponds to our distinction between fix-type and open-type verbs.

In Embick's analysis fix-type and open-type roots differ ontologically. ${ }^{44}$ The former are event-denoting roots that function as modifiers of a process $v$ head, as in (109). The stative component is provided by a Small Clause constituent. ${ }^{45}$ Verbs based on simple states are constructed in roughly the same way as what we have been assuming so far. In this case, the content of the stative predication is provided by the root, as in (110), which is a predicate of states. Thus, there are syntactic differences between the two classes of verbs, based on how the process and the stative components are integrated into the structure. This distinction can be straightforwardly extended to DM and ditransitive verbs.

$$
\begin{aligned}
& {\left[\ldots\left[{ }_{\mathrm{vP}}[\mathrm{v} \text { v } \mathrm{PROC} \sqrt{ } \text { ftiaxn- }]\left[\mathrm{sC} \mathrm{DP}_{\text {Theme }} \text { Pred }\right]\right]\right.} \\
& {\left[\ldots\left[\mathrm{vP}[\mathrm{v} \text { VPROC }]\left[\mathrm{sC} \mathrm{DP}_{\text {Theme }} \sqrt{ } \text { anigh- }\right]\right]\right.}
\end{aligned}
$$

What are the predictions for SP-licensing? To answer this question, we need to know how exactly the content of the stative component is determined, an issue that has remained somewhat unclear in the relevant literature. The issue is most crucial for fixtype verbs. Embick (2009:17) calls the Small Clause constituent (his 'ST') in (109) a 'proxy' state "whose identity is determined by the Root that is a predicate of $v$. [... If ST is empty, the meaning that is filled in is 'state caused by a breaking event' = broken." Similarly for our example fix. In (110), on the other hand, the meaning of the stative predicate in open-type verbs will be a simple state, e.g., 'being open.' Assuming that an additive operator takes scope over the Small Clause, the analysis seems to cut the pie correctly when it comes to the licensing of SPs. ${ }^{46}$

\footnotetext{
${ }^{43}$ Other SC-accounts of COS verbs can be found in Marantz (2009a, 2009b), Wood and Marantz (2015), Alexiadou et al. (2015), Ramchand (2008), a.m.o. See also Giannakidou and Merchant (1999) for an analysis that unifies Greek and English result verbs.

${ }^{44}$ Beavers et al. (2017) provide cross-linguistic evidence that also fix-type roots are state denoting. We have seen no reason to assume that Greek is an exception.

${ }^{45}$ Embick's analysis is built around the Bifurcation Thesis (BT), a hypothesis about the division of labor between encyclopedic-/root-meaning and templatic meaning, which dictates that if a meaning component can be provided by the template, then it must be provided by the template. The result state roots we have posited directly contradict BT. Given the discussion in this section we conclude that BT must be rejected as a strict grammatical principle. We refer to Beavers and Koontz-Garboden (2020) for extensive discussion and arguments against BT.

${ }^{46}$ The proposal is faced with a compositionality problem. Since the root that determines the content of the SC predicate is merged after the additive operator, it is not possible to fix the content of the additive presupposition at the SC level. Faced with a similar problem in generating the presuppositions of the morpheme $r e$-, Marantz (2009b) claims that $v P$ constitutes a non-compositional domain. We pursue a fully compositional account.
} 
Other researchers (e.g., Alexiadou et al. 2015; Alexiadou et al. 2017; a.o.) interpret an Embick-style analysis in a way that allows the predicate of the SC to be a simple state, even in the case of fix-type verbs. If so, an Embick-style analysis cannot derive the observed variation in the licensing of SPs; it needs to be augmented with further syntactic differences between fix-type and open-type verbs. One possibility is to assume that fix-type verbs, unlike open-type verbs, are Control-predicates, in the sense that the argument in the SC is PRO (cf. Beck and Johnson 2004; von Stechow 2007; a.o.), as in (111). The decomposition contains a stative component but does not allow the generation of SPs, since ke DP, like other quantificational DPs, cannot reconstruct in the position of PRO. Similar analyses could be provided for non-SP-generating DM and ditransitive verbs.

$$
\left[\ldots \text { vvP DP }_{\text {Theme }}[\mathrm{v}[\mathrm{v} \text { vPROC } \sqrt{ } \text { ftiaxn- }] \text { [sC PRO Pred ]]] }\right.
$$

We find no positive evidence for assuming such a distinction. We apply two diagnostics that have been developed in the literature on ditransitives. The crucial difference is that in Control analyses (and, similarly, 'complex predicate' analyses) the internal argument (the theme argument in POCs or the goal argument in DOCs) is an argument of the verb (or the VP) rather than an argument of the SC. It has been argued that this difference manifests itself in patterns of sub-extraction and inverse scope, so that sub-extraction in only possible under a Control analysis and inverse scope under a SC analysis. Applying the diagnostics to the proposed alternative, we expect that (i) sub-extraction should only be possible out of the internal arguments of nonSP-licensing verbs, since these are not subjects of SCs, and that (ii) in the case of two internal arguments in DM verbs and ditransitives, inverse scope should only be possible with non-SP-licensing verbs, since the two internal arguments are not arguments of the same predicate. No such differences can be observed. Sub-extraction is marginal, but, crucially, equally possible for all verbs, as shown in (112) for COS verbs. DM and ditransitive verbs behave similarly.
?Pianu anikse/ eftiakse to parathiro o Janis? whose opened fixed the window the John 'Whose window did John open/ fix?'

Similarly, inverse scope is possible for both SP-licensing and non-SP-licensing verbs, as shown in (113) for DM verbs. Ditransitives behave similarly. Whatever the explanation of these facts turns out to be, they provide no positive evidence for a syntactic distinction between SP-licensing and non-SP-licensing result verbs.

$$
\begin{aligned}
& \text { Bikan/ Efthasan dhio jiatri se kathe nosokomio. } \exists>\forall / \forall>\exists \\
& \text { entered arrived two doctors at every hospital } \\
& \text { 'Two doctors entered/ arrived at every hospital.' }
\end{aligned}
$$

Finally, an issue with any type of SC analysis concerns the fact that Greek does not allow other constructions that have been analyzed in terms of SC structures, 
like change-of-state resultatives, as in (114) (Giannakidou and Merchant 1999) and change-of-location, as in (60) above. ${ }^{47}$

* Maria sfirokopise to metalo isio.

the Mary hammered the metal straight

'Mary hammered the metal straight.'

Any account that permits SC-structures in the language, has to explain both (a) the availability of a SC structure for the result verbs we have been dealing with in the face of the ungrammaticality of resultatives, and (b) the difference between SP-licensing and non-SP-licensing verbs. There is tension between these two objectives. Consider an analysis that allows SC structures, but rules out resultatives by means of some independent principle. For expository purposes we use Folli and Harley (2005), as this account is closest to the Distributed Morphology framework we are assuming. ${ }^{48}$ Folli and Harley (2005) explain the ungrammaticality of resultatives based on obligatory overt 'Result-to-v' movement, where Result is the head of the SC constituent. Movement of Result will be blocked when a root is adjoined to little $v$, leading to ungrammaticality. Under the natural assumption that the root of, e.g., sfirokopao 'hammer' is a manner root adjoined to $v$, resultatives are predicted to be ungrammatical. In order to derive the availability of, e.g., directed motion verbs, we need to assume that the relevant roots are not manner roots modifying $v$ (unlike in the Embick-style analysis we have been pursuing so far), but rather that they specify the content of the Res(ult) head. If so, the locative PP is a modifier of Res, as in (115) for beno 'enter', rather than the head of the stative SC (cf. Ramchand 2008; Folli and Ramchand 2005).

$$
\left[\ldots\left[\mathrm{vP}[\mathrm{v} \text { VPROC }]\left[\operatorname{ResP} \mathrm{DP}_{\text {Theme }}\left[\operatorname{Res}[\operatorname{Res} \sqrt{ } \text { ben- }] \mathrm{PP}_{\mathrm{LOC}}\right]\right]\right]\right.
$$

The question, then, is how to distinguish between SP-generating DM verbs like beno 'enter' and non-SP-generating verbs like ftano 'arrive'. As far as we can see, the only available option is to unify the syntax of enter-and arrive-type of predicates, as in (116), and specify a semantic difference between the two roots, in terms of simple vs. result states. If so, the analysis is little more than a notational variant of the proposal we have defended in Sect. 5. The only difference is that instead of stative roots being verbalized directly, they project a Result Phrase/ SC first. In other words, a SC-based analysis will necessarily have to fall back to the semantic difference we have been assuming anyway.

$$
\left.\left[\ldots \text { vvP }_{\mathrm{v}} \text { VPROC }\right]\left[\operatorname{ResP} \mathrm{DP}_{\text {Theme }}[\operatorname{Res}[\operatorname{Res} \sqrt{ } \text { ben-/ } \sqrt{ } \text { ftan- }] \text { PP }]\right]\right]
$$

This section considered a possible alternative to the root-based analysis of the distribution of SPs presented in Sect. 5. We built this alternative based on Embick (2009),

\footnotetext{
${ }^{47}$ In other words, Greek is a 'verb-framed language' according to Talmy's parametrization. Notice that not everyone agrees that Talmy's parametrization is a genuine typological generalization, see e.g., Beavers et al. (2010). This is not an issue we need to take a stance on here. See Acedo-Matellán and Mateu (2013) for a recent overview of different accounts of Talmy's parametrization.

${ }^{48}$ Other accounts of this type are Acedo-Matellán and Mateu (2013) and Folli and Ramchand (2005). These analyses have been proposed as accounts of Talmy's typology that do not require structural differences between verb-framed and satellite-framed languages.
} 
an analysis that allows states to be provided by the templatic component. Any such analysis requires the introduction of non-trivial syntactic differences between SPlicensing and non-SP-licensing verbs. We argued that the required syntactic differences are not motivated. Moreover, the moment we take into account the fact that Greek disallows other resultative/SC structures, we need to revert to a unification of SP-licensing and non-SP-licensing verbs. The distinction between the two, then, can only be stated in semantic terms, as in the analysis defended in this paper.

\section{On semantic alternatives}

We provided a scopal account of Eventive-Stative Presuppositions that crucially relies on syntactic event decomposition. This section discusses possible alternative accounts that attempt to derive Eventive-Stative ambiguities without syntactic decomposition. In formulating the possible accounts, we rely on the relevant analyses that have been proposed to account for other grammatical phenomena that have been claimed to diagnose stative components within verbal decomposition. The best known and most discussed case is that of Repetitive Restitutive ambiguities of repetitive morphemes like again in (117). Another relevant phenomenon is that of temporal modification that appears to exclusively modify a result state. In (118a) for two hours imposes a restriction on the duration of John's being in the water, rather than on his jumping in the water. Similarly, in the relevant reading of (118b) the temporal modifier measures how long the car remained working after fixing, rather than how long the fixing lasted.

John opened the window again.

a. Repetitive Presupposition: John had opened the window before.

b. Restitutive Presupposition: The window had been open before.

a. John jumped in the lake for two hours.

b. Helen fixed the car for two hours. (Then it broke down again.)

Whereas many authors have taken such phenomena to provide evidence for syntactic event decomposition along the same lines as what we argued for Eventive-Stative ambiguities, others have proposed alternatives that do not rely on syntactic decomposition. Our primary aim in this section is to see if similar accounts can be used to explain the Eventive-Stative ambiguities of additive operators.

\subsection{The necessity of structure}

It has been suggested that the phenomena in (117) and (118) not only provide no justification for assuming syntactic decomposition of verbal predicates, but that they provide no evidence for verbal decomposition tout court. As Williams (2015:224) puts it, '[...] the adverb facts cannot, even in principle, justify a claim of strict lexical decomposition - more precisely, a claim that the semantic value of a verb is either structured or derived.' Instead, he proposes that certain adverbs can, by virtue of their meaning, describe not (only) the satisfiers of the predicate they modify, but (also) 
other things that those satisfiers are related to. To explicate he discusses cases of adjectival modification like blond child, where the modifier blond does not describe a child itself, but rather its hair (to which a child is related to by virtue of hair being parts of children). Williams argues that result state readings of adverbial modifiers also do not '[...] require hierarchical structure in the semantics of any verb, any more than the definition of blond requires structure in the meaning of any noun. It is enough that events should have structure - for example, that hardenings have an end - just like it is enough that children have hair' (Williams 2015:224). Of course, even if we accept this conclusion, we cannot simply assume a regular meaning for again and put the issue to rest. For one thing, the scope of an adverb like again is strictly determined by its syntactic argument. Moreover, in its usual repetitive interpretation again modifies the main event of a verbal predication not any of its sub-parts. Notice that we have made the same points for the additive operator. As discussed in Sect. 2 the content of the additive presupposition is strictly determined by the syntactic argument of ke DP, so that all the material in that argument is part of the content of the presupposition. Similarly, even when the complement of ke DP is a bare $\mathrm{V}$ or $\mathrm{VP}$, the additive presupposition cannot simply refer to any random sub-part of the event-decomposition. As mentioned before, any successful analysis should not only derive the presuppositions that are generated, but also explain why other possible presuppositions cannot be generated. For the cases discussed here, the task is to explain why result states are privileged in the way they are. The scopal theory explains this by appealing to properties of the proposed decomposition. Alternatives that deny the importance of any type of structured representation, on the other hand, minimally require an ambiguity account of the relevant operators and modifiers. Result states are privileged because there exists a second meaning of again that makes reference to result states, in one way or other. ${ }^{49}$ Notice that, although on methodological grounds ambiguity accounts are in principle better to be avoided unless otherwise necessary, an ambiguity account of adverbs of repetition is, in fact, initially plausible given the diachrony of such elements. Work in Germanic languages has shown them to be diachronically related to or even directly derived from elements exclusively denoting restitution or reversal (see Fabricius-Hansen 1980 for German wieder, Gergel and Beck 2015 for Early English, Zwarts 2019 for Dutch).

This type of approach suffers from an over-generation problem, however, as it fails to explain variation in the availability of result state readings. Such variation has occasionally been pointed out for the availability of restitutive readings of again. Here we demonstrate with SPs. Any account that would attempt to explain the generation of SP without appealing to any level of structured representation would need to explain the difference between, e.g., the SP-generating verb anigho 'open' and the non-SP-generating verb ftiaxno 'fix' or the difference between the SP-generating verb petheno 'die' and the non-SP-generating verbs skotono 'kill' and pnigho 'drown'. A proponent of the envisaged alternative would have to claim that, while being open is part of an opening, particularly its end, being in a working condition is not part of a fixing. Similarly, that being dead is part of a dying but not part of a killing or a drowning. We find this very implausible given that all these verbs necessarily pick up events

${ }^{49}$ Williams (2015) recognizes this, of course, and adopts the proposal of Dowty (1979), while rejecting the necessity of any syntactic derivation or structured representation of verbal meaning. 
which have easily identifiable states as their parts, as discussed in Sect. 4. The same over-generation problem is present in every approach that dissociates the description of a result state from the verb. For example, Jäger and Blutner (2000) propose that result states are specified by a function RESULT that applies on a proposition and returns a proposition that is a result of the input proposition. In such an approach too, then, it has to be claimed that, e.g., being dead is a result of dying, but not of killing or drowning. ${ }^{50,51}$ We conclude that the variation in the distribution of SPs (and probably of result readings of other modifiers and operators) provides a strong argument in favor of theories that allow verbs to include qualitative descriptions of their result states.

\subsection{Dowty (1979)}

One such theory that still does not require syntactic decomposition for the generation of restitutive readings is provided in Dowty (1979) ${ }^{52}$ There the content of result states is specified in lexical entries that provide representations of the meaning of individual verbs using event decompositions. A second, 'restitutive' entry of again, again $_{\text {res }}$ related to the original repetitive entry via a meaning postulate, allows again to apply on the part of the formula that describes the result state. Moving to additives, assume that example (16), repeated below in (119), has the partial syntactic representation in (120).

O Janis anikse ke to PARATHIRO.

the John opened also the window

'John opened the window too.'

[VP [DP o Janis ] [v' [v anikse] [DP ke to parathiro ]]]

The meaning postulate says that the semantic representation in (121) is equivalent to the representation in (122), where $T O O_{e v}$ is a regular additive operator. We have omitted several important details here, but it should be clear that an approach along these lines should be able to generate a SP. The account is also in principle able to account for differences in the distribution of SPs by specifying different decompositions for different classes of result verbs or specifying different stative components for different individual verbs.

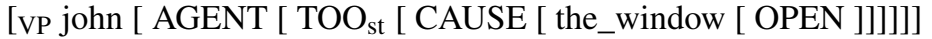 [vP john [ AGENT [ CAUSE [ TOO ${ }_{\mathrm{ev}}$ [ the_window [ OPEN ]]]]]]}

\footnotetext{
${ }^{50}$ See von Stechow $(2000,2001$ a) for a careful dissection of the proposal in Jäger and Blutner (2000).

${ }^{51}$ A related approach for again is presented in Neeleman and Van de Koot (2017), where it is argued that under certain circumstances, a repetitive presupposition is weakened to a restitutive presupposition. However, the authors assume a single entry for again and provide no explicit procedure that determines the content of the weakening. Thus, the proposal fails to capture both the exceptional status of result states and the distribution of result state readings. Moreover, the proposal seems to be inapplicable to the cases at hand as it relies heavily on properties of free focus that are not relevant here. It would take us too far to discuss this issue in detail here.

${ }^{52}$ See Kamp and Rossdeutscher (1994) for a related axiomatic account in a dynamic framework.
} 
A usual argument against axiomatic accounts like Dowty (1979) and Jäger and Blunter (2000) is that they cannot explain the bleeding of restitutive readings of again when it appears in certain syntactic positions (von Stechow 1996). Similar facts obtain with fronted ke DPs in a left-peripheral position, as we have seen in (30). It seems that the best axiomatic accounts can do in this case is impose different c-selectional restrictions on the different versions of the relevant operators and modifiers. As Bale (2007) observes, however, not even this descriptive device is able to explain the bleeding of restitutive presuppositions of again when all that causes the unavailability of restitution is insertion of an intersective adverbial modifier, which does not change the category of the constituent it attaches to. Both accounts predict that an intersective modifier cannot interfere with the availability of the result phrase. As before, the argument can be replicated with additive operators. Consider the contrast between (124) and (125) in the context of (123).

\section{Context for Stative Presupposition:}

John owns a puppy and a kitten. Both were born in his apartment, the puppy in the kitchen and the kitten in the living room. Both stayed in their own rooms, until, three days after they were born, ...

bike ke to KUTAVI sto saloni.

entered also the puppy at.the living room

'The puppy entered the living room too.'

\#bike ke to KUTAVI stis dhio i ora sto saloni.
entered also the puppy at.the two the hour at.the living room
'The puppy entered the living room at two o'clock too.'

Whereas, as we have seen, (124) can generate a SP, no SP is available in (125), where a VP temporal modifier has been inserted. Recall that we know from Sect. 2 that adverbial modifiers that linearly follow pre-verbal or post-verbal subjects, are in the scope of those subjects. A proponent of the axiomatic account would have to claim, then, that the position of ke DP in (124) and (125) is different. Whereas the additive operator in (124) is a VP-related $T O O_{s t}$, the additive in (125) is related to a higher position, which, by stipulation, is only available for $T O O_{e v}$. Crucially, the difference should result from the presence of an intersective modifier, which, however, is known not to change the label of the constituent it modifies or affect the syntactic position of DPs above it. ${ }^{53,54}$

\footnotetext{
${ }^{53}$ The scopal account captures the contrast under the natural assumption that the temporal modifier attaches on an eventive constituent. Since ke DP in a higher position has to have the modifier in its scope, only an Eventive Presupposition can be generated.

${ }^{54}$ Another alternative to a scopal analysis of the Repetitive-Restitutive ambiguity of again is based on defining the meaning of the restitutive version of again, again $_{c d}$, in terms of counter-directionality (Fabricius-Hansen 1983, 2001; Pedersen 2014; Beck and Gergel 2015; a.o.). A counter-directional version of the additive operator would generate a presupposition along the lines of (i). We leave it to the reader to establish that (i) both under- and over-generates felicitous uses $k e$ 'also'.
}

(i) Counter-directional Presupposition: Something other than the window closed. 


\subsection{Accessible states}

Other phrasal phenomena that require access to result states have been dealt with by allowing the stative component to be accessible for semantic composition. This is achieved without the need for syntactically accessible stative constituents by assuming that result verbs have an additional result state argument, as in (126) for anigho 'open' and ftiaxno 'fix'. Piñón (1999) assumes a version of such entries in order to derive result readings of temporal modifiers as in (118) above. The temporal modifier, itself a predicate of eventualities, simply adds a restriction on the predicate of states in the usual intersective fashion. Kratzer (2000) assumes similar entries in her analysis of target state passives in German.

$$
\begin{aligned}
& \text { a. } \llbracket \text { anigho } \rrbracket=\lambda x \lambda s \lambda e . \operatorname{open}(\mathrm{x})(\mathrm{s}) \& \operatorname{process}(\mathrm{e}) \& \operatorname{CAUSE}(\mathrm{s})(\mathrm{e}) \\
& \text { b. } \llbracket \text { ftiaxno } \rrbracket=\lambda \mathrm{x} \lambda \mathrm{s} \lambda \mathrm{e} . \operatorname{intact}(\mathrm{x})(\mathrm{s}) \& \operatorname{fix}(\mathrm{e}) \& \operatorname{CAUSE}(\mathrm{s})(\mathrm{e})
\end{aligned}
$$

The entries in (126) cannot be used to license SPs of additive operators, however. After existentially closing the event variable via application of a stativizer (Kratzer 2000) (or, alternatively, via application of some version of Function Composition), the entries can compose with our regular entry for ke DP. But such a derivation fails to derive SPs, as the CAUSE component remains in the scope of the additive. ${ }^{55}$

The only option to pursue this line further is to assume a second entry for the additive operator, one that extracts the stative component out of the denotations in (126). von Stechow (2001a, 2004) notices a similar issue in deriving restitutive readings of again with the lexical entries like (126). He proposes to treat result states as intensional properties, properties of times, rather than individual states. ${ }^{56}$ If so, it is possible to define a second version of again that derives a Restitutive Presupposition. Adapting slightly for current purposes, the relevant entries for SPs are as in (127), for the SP-generating verb anigho 'open', and (128) for the stative additive operator (where $i$ the type of time intervals, $t$ a variable over time intervals). ${ }^{57}$ The presupposition that is generated is that the property of being open is true at some interval of some individual other than the associate of the additive, which seems adequate.

$$
\begin{aligned}
& \llbracket \text { anigho } \rrbracket=\lambda \mathrm{x}_{\mathrm{e}} \lambda \mathrm{e}_{\mathrm{s}} \lambda \mathrm{t}_{\mathrm{i}} \lambda \mathrm{P}_{\mathrm{e}, \mathrm{it}} . \mathrm{BECOME}_{\mathrm{e}}(\mathrm{P}(\mathrm{x})(\mathrm{t})) \& \mathrm{P}(\mathrm{x})(\mathrm{t})=\mathrm{open}(\mathrm{x})(\mathrm{t}) \\
& \llbracket \mathrm{ke}_{\mathrm{SP}}(\mathrm{DP}) \rrbracket=\lambda \mathrm{R}_{<\mathrm{e}<\mathrm{s}<\mathrm{i}<<\mathrm{e}, \mathrm{it}>\mathrm{t}>>>>} \lambda \mathrm{e}_{\mathrm{s}} \lambda \mathrm{t}_{\mathrm{i}} \lambda \mathrm{P}_{\mathrm{e}, \mathrm{it}}: \exists \mathrm{t}^{\prime} \mathrm{x}_{\mathrm{e}} \in \llbracket \mathrm{DP} \rrbracket^{\mathrm{A}} \& \\
& \mathrm{x} \neq \llbracket \mathrm{DP} \rrbracket \& \mathrm{P}(\mathrm{x})\left(\mathrm{t}^{\prime}\right) . \mathrm{R}(\llbracket \mathrm{DP} \rrbracket)(\mathrm{e})(\mathrm{t})(\mathrm{P})
\end{aligned}
$$

\footnotetext{
${ }^{55}$ In their analysis of German -ung nominalizations, Roßdeutscher and Kamp (2010) propose a dynamic version of this approach, according to which result verbs make available a discourse referent for a state $s$. The analysis allows -ung to pick $s$ as the denotation of the nominalization, but $s$ should still satisfy all conditions imposed on it (i.e., it should be caused by a preceding event). It, thus, generates eventive presuppositions only.

${ }^{56}$ This characterization of result states is very close to 'Kimian states' in Maienborn (2005). See Pross (2019), Pross and Roßdeutscher (2019) for a recent characterization of (at least some) result states as 'Kimian states.'

${ }^{57}$ These are indicative entries that allow us to present the logic of the approach. It would take us too far afield to provide an explicit analysis along these lines. We have used the notation in von Stechow (2001a), which the interested reader can refer to for some more details.
} 
As before, verbs that do not generate SPs differ in that they do not make the result state available, as in (129) for ftiaxno 'fix' (cf. von Stechow's 2001a entry for German putzen 'clean' that fails to license restitutive readings of again). (129) can only combine with the regular eventive entry of the additive, giving rise to an Eventive Presuppposition.

$$
\llbracket \text { ftiaxno } \rrbracket=\lambda \mathrm{x}_{\mathrm{e}} \lambda \mathrm{e}_{\mathrm{s}} . \operatorname{BECOME}_{\mathrm{e}}(\operatorname{intact}(\mathrm{x}))
$$

The analysis we just sketched is, in principle, capable of deriving SPs and their distribution. At the same time, however, it relies on both (i) an ambiguity account of the additive operator, and (ii) a type difference between, what we have called, simple state roots, which do generate SPs, and result state roots, which do not. Starting with the latter, we have seen in Sects. 5 and 6 and in the references mentioned there that there appears to be no positive evidence from other derivational processes affecting these roots for such a difference. An ambiguity analysis of the additive operator itself seems even less plausible. Whereas, as we have mentioned, there is some reason from the diachrony of repetitive elements to plausibly assume a special connection to result states, no such justification can be provided for additive operators, which, at least in Greek, have no etymological or other connection to restitution or reversal. More importantly, even if we accept the necessity of (i) and (ii), the accounts are faced with an empirical challenge. The accounts are built to unify the behavior of phrasal phenomena that require access to result states and reduce the generation of SPs to the mechanisms that generate result readings of for-phrases or restitutive presuppositions of again. This straightforwardly predicts that they should have the same distribution across classes of result verbs. Although we have not conducted a full investigation at this stage, it is immediately clear that the different phenomena do not have the same distribution among verb classes. SPs, in particular, have a stricter distribution than all other phenomena mentioned here (result state for-phrases, restitutive readings of again, German target state passives and -ung nominalizations). To mention just a single example, whereas ftiaxno 'fix' licenses result state readings of temporal modifiers, as in (118b) (the judgment is the same in Greek), it does not give rise to SPs. But under an analysis along the lines of (127)-(129), for-phrases are also predicted to be unavailable for ftiaxno 'fix'. The scopal analysis defended in this paper, on the other hand, can in principle derive such differences. If, for example, result state readings of temporal modifiers simply require access to a variable of states, simple and result state roots are both predicted to allow them. At the same time, since the content of additive presuppositions is sensitive to the content of its scope, the two roots are predicted to differ in the generation of SPs. More generally, it is expected that, everything else being equal, modification of result states should be more permissive than scopal phenomena like SPs. ${ }^{58}$

\footnotetext{
${ }^{58}$ It is not entirely clear that everything else is indeed equal. For example, modifiers of result states are part of the at-issue meaning and as such are expected to interact with other operators, like CAUSE, BECOME, etc. This interaction might restrict their availability in ways that are independent of the structural licensing conditions discussed here. We also do not wish to claim that all the phenomena mentioned above have the same structural licensing conditions. We cannot decide that without a clear picture of their distributions and how those compare with each other.
} 


\subsection{Section summary}

In this section we strengthened our conclusion that the Eventive-Stative ambiguities of additive operators necessitate decomposition of verbal predicates by dismissing accounts that dissociate the description of the result state from the verb itself. Moreover, the failure of axiomatic accounts strengthens our conclusion that the decomposition is syntactic. The failure of scalar, counter-directional accounts strengthens our conclusion that SPs require event decomposition. Alternatives that rely on the semantic accessibility of result states can, in principle, explain the basic facts about SPs and their distribution, but under the penalty of assuming (i) a perhaps non-standard semantic treatment of result states, (ii) an unmotivated ambiguity account of the additive operator, (iii) unmotivated type differences between, e.g., open- and fix-type verbs, and (iv) a restricted flexibility in capturing differences in the distribution of different phrasal phenomena that require access to result states.

\section{Open issues and future directions}

This section discusses briefly a number of issues that are left open in the current investigation and identifies some possible ways to address them. We first focus on issues related to formulating a comprehensive theory of verbal decomposition, before turning to issues related to variation in the availability of SPs.

We have provided positive evidence for event decomposition and the syntactic accessibility of stative constituents within verbal decomposition. This evidence regards a subset of result verbs, the ones that can support stative readings of additive operators. As mentioned throughout the paper, even though the generation of SPs narrows down the possible analyses of this subset, it leaves open a number of possibilities. These regard particularly the choice of the operators that operate on (result) states (BECOME vs. CAUSE vs. PROCESS, a.o.). The different choices interact in interesting ways with theories of other aspects of grammatically relevant verbal meaning (telicity, durativity, etc.) that we have not attempted to integrate in the analysis. The choices multiply when it comes to the analyses of other result verbs, like Incremental Theme verbs and verbs that make reference to entities like degrees and vectors. Apart from a proper characterization of the available operators, we require a more complete characterization of the grammatically relevant aspects of root meaning. We argued for the distinction between 'result state' and 'simple state' roots. It is left open whether other 'templatic' meanings can appear in the meaning of roots (causation, agentivity, intentionality, etc.). ${ }^{59}$ All the issues mentioned here can benefit from a more complete investigation of additive operators, and particularly from the properties and distribution of 'intermediate readings' and the interaction of additive operators with adverbial modifiers and other operators that have been argued to detect various properties of verbal decomposition. Of particular interest for the domain of investigation of the current paper is the interaction of additive operators with other phrasal phenomena that detect result states.

\footnotetext{
${ }^{59}$ See Bale (2007), Ausensi (2020) for relevant discussion in the context of repetitive presuppositions of again. As far as we can see, their arguments can be reproduced with additive operators.
} 
A cross-linguistic investigation of sub-lexical readings of additive operators can also potentially be very informative, since it is known that languages can differ in the behavior of (sub-classes of) result verbs and in the types of decompositions they admit. To mention just one relevant case, recall Talmy's Generalization and the distinction between verb- and satellite-framed languages. This paper has focused on Greek, a verb-framed language. Under at least some analyses of the distinction, satelliteframed languages will admit additional structures (roughly speaking, Small Clause structures) that can potentially generate SPs. It is possible then that these languages show fewer restrictions on the generation of SPs. ${ }^{60}$ Whether they actually do or not will, of course, depend on further properties of Small Clauses, as discussed in Sect. 6.

Any cross-linguistic investigation, however, should be aware of a further complication. It is known that adverbial modifiers can differ in whether they admit result state readings. The same can be shown for SPs. Unlike ke, the Greek additive operator episis 'also' can only give rise to Eventive Presuppositions, as in (131).

$$
\begin{aligned}
& \text { O Janis anikse episis to PARATHIRO. } \\
& \text { the John opened also the window } \\
& \text { 'John opened the window too.' }
\end{aligned}
$$

a. Eventive Presupposition: John opened something other than the window.

b. \#Stative Presupposition: Something other than the window is open.

Rapp and von Stechow (1999), Beck (2005) propose that a 'Visibility Parameter' specifies for each individual adverb whether they can have access to a result state or not. Pedersen (2014) proposes that only scalar operators with access to a measure function can give rise to what appear to be result state readings. As we have seen, the behavior of the Greek non-scalar additive ke shows clearly that not all result state readings can be reduced to scalarity. There are various ideas one could pursue to explain the difference between individual additive operators. To mention one possibility, we could try to exploit differences in the discourse function of such operators and appeal to known characterizations of Focus Associating Operators that make crucial use of such distinctions (as in e.g., Beaver and Clark 2008). We cannot pursue these avenues further, however, without a clearer picture of the behavior of different FAOs with regard to SPs and related phenomena.

\section{Conclusions}

The Eventive-Stative Ambiguities of additive operators like Greek ke 'also' that are exhibited by a sub-class of result verbs provide important positive evidence for eventdecompositional approaches to verbal decomposition. At the same time, the distribution of Eventive-Stative ambiguities is more readily captured if incrementality-based

\footnotetext{
${ }^{60}$ For example, the presence of manner might not necessarily block result state readings, if manner is not represented within the Small Clause constituent. This has been argued to be the case for manner ditransitive verbs. Beavers and Koontz-Garboden (2020) report that verbs like English kick license restitutive readings of again.
} 
and scalar approaches to verbal decomposition are also available for different subclasses of result verbs. These different approaches to the syntax and semantics of verbal predicates, then, shouldn't be seen as necessarily incompatible or in competition. Rather, we should aim to determine when and why they apply and how their primitives can interact within a comprehensive theory of verbal decomposition. We have proposed a partial resolution of these issues by establishing the primitives necessary to generate SPs and by linking the availability of different decompositions with the content of different types of roots. To reiterate briefly: (i) Change of State, Directed Motion and ditransitive verbs are built out of stative roots which can be taken up by CAUSE and BECOME operators. The availability of SPs depends on the content of the individual roots. (ii) Degree Achievements are built out of roots denoting measure functions and allow both event-decompositional and scalar derivations, depending on the application of further operators, like verbal versions of POS, COMP, etc. The availability of event-decompositional derivations explains the general availability of SPs with this sub-class. (iii) Incremental Theme verbs are built out of eventive roots and thus cannot give rise to SPs. The resulting picture fits well within current, independently motivated classifications of result verbs, minimizes syntactic and semantic non-uniformity within the sub-classes of result verbs, and requires nothing special to be said about the additive operator.

The analysis depends on a strict separation between encyclopedic and nonencyclopedic ('templatic') components, which is already present at the syntactic level. We proposed to capture this separation in the Distributed Morphology framework where encyclopedic meaning is associated with the contribution of roots and non-encyclopedic ('templatic') meaning with the contribution of functional heads within the verbal projection. It is crucial in this set-up that the stative meaning required for the generation of SPs is provided by the root itself, especially in a verbframed language like Greek. We have strengthened these conclusions by considering possible syntactic alternatives that relate result states to Small Clause constituents and possible semantic alternatives that do not require syntactic decomposition. It was shown that (i) no approach can do without some type of syntactic event decomposition, (ii) no approach can do without a distinction in the basic, encyclopedic content provided by SP-generating and non-SP-generating COS, DM, and ditransitive verbs, (iii) all alternative approaches face empirical challenges that do not affect the present proposal, and (iv) alternative approaches come at the cost of assuming either unmotivated polysemy of the additive operator or unmotivated syntactic and semantic non-uniformity within sub-classes of result verbs or both. We conclude that the generation of SPs by additive operators is currently the most reliable diagnostic for the detection of syntactically accessible result states in verbal decomposition.

Acknowledgements We would like to thank three anonymous NLLT reviewers and our handling editor for their detailed and helpful work on our manuscript. We are grateful to Fabienne Martin, Louise McNally and Artemis Alexiadou for their comments on previous versions of the manuscript and to Florian Schäfer, Margaret Grant, John Beavers, Nino Grillo, Elena Anagnostopoulou, Winnie Lechner, Itamar Kastner, Arhonto Terzi, Stergios Chatzikyriakidis, as well as audiences at GLOW39, IGG42, ISTAL22 and the universities of York and Utrecht for useful comments and suggestions. Last but not least, we would like to thank our friends and students who provided the judgments reported in this paper. During this project, the first author was initially supported by SFB 732 Incremental Specification in Context at the University of Stuttgart and later by DFG AL 554/8-1 (Gottfried Wilhelm Leibniz Prize to Artemis Alexiadou) at 
the Humboldt University of Berlin and by the DFG project 'Relative measurement and the DP border' at Leibniz Zentrum Allgemeine Sprachwissenschaft, all of which are gratefully acknowledged.

Funding Note Open Access funding enabled and organized by Projekt DEAL.

Publisher's Note Springer Nature remains neutral with regard to jurisdictional claims in published maps and institutional affiliations.

Open Access This article is licensed under a Creative Commons Attribution 4.0 International License, which permits use, sharing, adaptation, distribution and reproduction in any medium or format, as long as you give appropriate credit to the original author(s) and the source, provide a link to the Creative Commons licence, and indicate if changes were made. The images or other third party material in this article are included in the article's Creative Commons licence, unless indicated otherwise in a credit line to the material. If material is not included in the article's Creative Commons licence and your intended use is not permitted by statutory regulation or exceeds the permitted use, you will need to obtain permission directly from the copyright holder. To view a copy of this licence, visit http://creativecommons.org/licenses/by/4.0/.

\section{References}

Abusch, Dorit. 1986. Verbs of change, causation and time, Vol. 50. Stanford: Center for the Study of Language and Information, Stanford University.

Acedo-Matellán, Victor, and Jaume Mateu. 2013. Satellite-framed Latin vs. verb-framed Romance: A syntactic approach. International Journal of Latin and Romance Linguistics 25(2): 227-265.

Alexiadou, Artemis, Elena Anagnostopoulou, and Florian Schäfer. 2006. The properties of anti-causatives cross-linguistically. In Phases of interpretation, ed. Mara Frascarelli. Berlin: Mouton.

Alexiadou, Artemis, Elena Anagnostopoulou, and Florian Schäfer. 2015. External arguments in transitivity alternations: A layering approach. Vol. 55 of Oxford studies in theoretical linguistics.

Alexiadou, Artemis, Fabienne Martin, and Florian Schäfer. 2017. Presented at Roots V conference. London: Queen Mary University of London/University College.

Anagnostopoulou, Elena. 2003. The syntax of ditransitives: Evidence from clitics (Vol. 54). Berlin: de Gruyter.

Anagnostopoulou, Elena, and Yota Samioti. 2013. Allosemy, idioms and their domains: Evidence from adjectival participles. In Syntax and its limits, eds. Raffaella Folli, Christina Sevdali, and Robert Truswell, 218-250. Oxford: Oxford University Press.

Anagnostopoulou, Elena, and Yota Samioti. 2014. Domains within words and their meanings: a case study. In The syntax of roots and the roots of syntax, eds. Artemis Alexiadou, Hagit Borer, and Florian Schäfer, 81-111. Oxford: Oxford University Press.

Ausensi, Josep. 2020. Agent entailments in the semantics of roots, eds. Ryan Budnick, and Nari Rhee. University of Pennsylvania Working Papers in Linguistics 26(1).

Baker, Mark C. 1988. Incorporation: A theory of grammatical function changing. Chicago: University of Chicago Press.

Baker, Mark C. 1997. Thematic roles and syntactic structure. In Elements of grammar, 73-137. Dordrecht: Springer.

Bale, Alan Clinton 2007. Quantifiers and verb phrases: An exploration of propositional complexity. Natural Language \& Linguistic Theory 25(3): 447-483.

Barss, Andrew, and Howard Lasnik. 1986. A note on anaphora and double objects. Linguistic Inquiry 17: $347-354$

Beaver, David I., and Brady Z. Clark. 2008. Sense and sensitivity: How focus determines meaning. Chichester: Wiley-Blackwell.

Beavers, John. 2011a. An aspectual analysis of ditransitive verbs of caused possession in English. Journal of Semantics 28: 1-54.

Beavers, John. 2011b. On affectedness. Natural Language \& Linguistic Theory 29(2): 335-370.

Beavers, John. 2013. Aspectual classes and scales of change. Linguistics 51(4): 681-706.

Beavers, John, and Andrew Koontz-Garboden. 2012. Manner and result in the roots of verbal meaning. Linguistic inquiry 43(3): 331-369. 
Beavers, John, and Andrew Koontz-Garboden. 2017. Result verbs, scalar change, and the typology of motion verbs. Language 93(4): 842-876.

Beavers, John, and Andrew Koontz-Garboden. 2020. The roots of verbal meaning, Oxford: Oxford University Press.

Beavers, John, Michael Everdell, Kyle Jerro, Henri Kauhanen, Andrew Koontz-Garboden, Elise LeBovidge, and Stephen Nichols. 2017. Two types of states: A cross-linguistic study of changeof-state verb roots. Proceedings of the Linguistic Society of America 2(38): 1-15.

Beavers, John, Beth Levin, and Shiao Wei Tham. 2010. The typology of motion expressions revisited. Journal of linguistics 46(2): 331-377.

Beck, Sigrid. 2005. There and back again: A semantic analysis. Journal of semantics 22(1): 3-51.

Beck, Sigrid, and Remus Gergel. 2015. The diachronic semantics of English again. Natural Language Semantics 23(3): 157-203.

Beck, Sigrid, and Kyle Johnson. 2004. Double objects again. Linguistic inquiry 35(1): 97-123.

Bochnak, M. Ryan. 2010. Two sources of scalarity in the verb phrase. Subatomic semantics of event predicates. Dordrecht: Springer (to appear).

Borer, Hagit. 2003. Exo-skeletal vs. endo-skeletal explanations: Syntactic projections and the lexicon. In The nature of explanation in linguistic theory, 31-67.

Borer, Hagit. 2005. Structuring sense. Oxford: Oxford University Press.

Borer, Hagit. 2009. Roots and categories. Presented at the 19th Colloquium on Generative Grammar. University of the Basque Country, Vitoria-Gasteiz.

Bruening, Benjamin. 2001. QR obeys superiority: Frozen scope and ACD. Linguistic inquiry 32(2): 233273.

Bruening, Benjamin. 2010. Ditransitive asymmetries and a theory of idiom formation. Linguistic Inquiry 41(4): 519-562.

Bruening, Benjamin. 2019. Experiments reveal that scope is not frozen in English double object constructions. Ms., University of Delaware. Available at https://udel.edu/ bruening/Downloads/ ScopeExperiments1.pdf. Last accessed 26/08/2019.

Canakis, Costas. 1996. Kai: The story of a conjunction. Unpublished PhD dissertation, University of Chicago.

Chatzikyriakidis, Stergios, Dimitris Michelioudakis, and Giorgos Spathas. 2015. Greek focus operators and their associates. In Proceedings of AMGL 35, eds. Giorgos Papanastasiou, Dimitris Koutsogiannis, and Maria Theodoropoulou, 167-179. Thessaloniki: Insitute of Modern Greek Studies.

Copley, Bridget, and Heidi Harley. 2015. A force-theoretic framework of event structure. Linguistics and Philosophy 38: 103-158.

Dixon, R. M. W. 1982. Where have all the adjectives gone? And other essays in semantics and syntax. The Hague: Mouton.

Dobler, Eva. 2008. Again and the structure of result states. ConSOLE 15: 41-66.

Dowty, David R. 1979. Word meaning and Montague grammar: The semantics of verbs and times in generative semantics and in Montague's PTQ. Number 7 in Synthese Language Library. Dordrecht: Reidel.

Embick, David. 2009. Roots and states. 20-21. Presented at the Root Bound workshop, University of Southern California.

Fabricius-Hansen, Cathrine. 1980. Lexikalische Dekomposition, Bedeutungspostulate und wieder. Perspektiven der lexikalischen Semantik, Bonn 26: 40.

Fabricius-Hansen, Cathrine. 1983. Wieder ein wieder? Zur Semantik von wieder. In Meaning, use and interpretation of language, 97-120.

Fabricius-Hansen, Cathrine. 2001. Wi(e)der and again(st). In Audiatur vox sapientiae: A Festschrift for Arnim von Stechow, eds. Caroline Féry and Wolfgang Sternefeld, 101-130. Berlin: Akademie Verlag.

Filip, Hana. 2012. Lexical aspect. In The Oxford handbook of tense and aspect, ed. Robert I. Binnick. Oxford: Oxford University Press.

Filip, Hana. 2020. Lexical aspect. In The Blackwell companion to semantics, eds. Lisa Matthewson, Cécile Meier, Hotze Rullman, and Ede Zimmermann. Hoboken: Wiley Publishing.

Folli, Raffaella, and Heidi Harley. 2005. Consuming results in Italian and English: Flavors of v. In Aspectual inquiries, eds. Paula Kempchinsky, and Roumyana Slabakova, 95-120. Dordrecht: Springer.

Folli, Raffaella, and Gillian Ramchand. 2005. Prepositions and results in Italian and English: An analysis from event decomposition. In Perspectives on aspect, eds. Henk Verkuyl, Henriette De Swart, and Angeliek van Hout, 81-105. Dordrecht: Kluwer Academic.

Gehrke, Berit. 2008. Ps in motion: On the semantics and syntax of P elements and motion events. PhD Diss., Utrecht University. LOT Dissertation Series 184. 
Gehrke, Berit, and Marika Lekakou. 2013. How to miss your preposition. In Studies in Greek linguistics 33, ed. Melita Stavrou 92-106. Thessaloniki: Institute of Modern Greek Studies.

Georgala, Efthymia. 2012. Applicatives in their structural and thematic function: A minimalist account of multitransitivity. PhD diss., Cornell University.

Gergel, Remus, and Sigrid Beck. 2015. Early Modern English again: A corpus study and semantic analysis. English Language \& Linguistics 19(1): 27-47.

Giannakidou, Anastasia. 2007. The landscape of EVEN. Natural Language and Linguistic Theory 25: 39-81.

Giannakidou, Anastasia, and Jason Merchant. 1999. Why Giannis can't scrub his plate clean: On the absence of resultative secondary predication in Greek. In Greek Linguistics '97: Proceedings of the 3rd international conference on Greek linguistics, eds. Amalia Moser et al., 93-103. Athens: Ellinika Grammata.

Goldschmidt, Anja, and Joost Zwarts. 2016. Hitting the nail on the head: Force vectors in verb semantics. In Semantics and Linguistic Theory (SALT) 26, eds. Mary Moroney, Carol-Rose Little, Jacob Collard, and Dan Burgdorf.

Green, Georgia M. 1974. Semantic and syntactic regularity. Bloomington: Indiana University Press.

Grimshaw, Jane. 1990. Argument structure. Cambridge: MIT Press.

Hale, Ken, and Samuel J. Keyser. 1993. On argument structure and the lexical expression of syntactic relations. In The view from Building 20, eds. Ken Hale and Samuel J. Keyser, 53-109. Cambridge: MIT Press.

Halle, Morris, and Alec Marantz. 1993. Distributed morphology and the pieces of inflection. In The view from Building 20, eds. Ken Hale and Samuel J. Keyser, 111-176. Cambridge: MIT Press.

Harley, Heidi, and Shigeru Miyagawa. 2017. Syntax of ditransitives. In Oxford research encyclopedia of linguistics, ed. Mark Aronoff. Oxford: Oxford University Press.

Harley, Heidi. 1997. If you have, you can give. In West Coast Conference on Formal Linguistics (WCCFL) 15, 193-207. Stanford: CSLI Publications.

Harley, Heidi. 2002. Possession and the double object construction. Linguistic variation yearbook 2(1): $31-70$.

Harley, Heidi. 2005. How do verbs get their names? Denominal verbs, manner incorporation, and the ontology of verb roots in English. In The syntax of aspect, eds. Nomi Erteschk-Shir and Tova Rapoport. Oxford: Oxford University Press.

Harley, Heidi. 2014. On the identity of roots. Theoretical linguistics 40(3-4): 225-276.

Hay, Jennifer, Christopher Kennedy, and Beth Levin. 1999. Scalar structure underlies telicity in "degree achievements". Semantics and Linguistic Theory (SALT) 9: 127-144.

Heim, Irene, and Angelika Kratzer. 1998. Semantics in generative grammar (Vol. 1185). Oxford: Blackwell.

Higginbotham, James. 2000. On events in linguistic semantics. In Speaking of events, eds. James Higginbotham, Fabio Pianesi, and Achille C. Varzi. Oxford: Oxford University Press.

Horrocks, Geoffrey, and Melita Stavrou. 2003. Actions and their results in Greek and English: The complementarity of morphologically encoded (viewpoint) aspect and syntactic resultative predication. Journal of Semantics 20(3): 297-327.

Horrocks, Geoffrey, and Melita Stavrou. 2007. Grammaticalised aspect and spatio-temporal culmination. Lingua 117.

Jäger, Gerhard, and Reinhard Blutner. 2000. Against lexical decomposition in syntax. In Proceedings of IATL 15, ed. Adam Z. Wyner, 113-137. Haifa: University of Haifa.

Kamp, Hans, and Antje Rossdeutscher. 1994. Remarks on lexical structure and DRS construction. Theoretical linguistics 20(2-3): 97-164.

Karttunen, Lauri, and Stanley Peters. 1979. Conventional implicature. In Syntax and semantics 11: Presupposition, eds. Choon-kyu Oh and David A. Dinneen, 1-56. New York: Academic Press.

Kearns, Kate. 2007. Telic senses of deadjectival verbs. Lingua 117: 26-66.

Kennedy, Christopher. 2007. Vagueness and grammar: The semantics of relative and absolute gradable adjectives. Linguistics and Philosophy 30(1): 1-45.

Kennedy, Christopher. 2012. The composition of incremental change. In Telicity, change, state: a crosscategorical view of event structure, eds. Violeta Demonte and Louise McNally. Oxford: Oxford University Press.

Kennedy, Christopher, and Beth Levin. 2008. Measure of change: The adjectival core of verbs of variable telicity. In Adjectives and adverbs: Syntax, semantics and discourse, eds. Louise McNally and Christopher Kennedy, 156-182. New York: Oxford University Press. 
Koontz-Garboden, Andrew. 2005. On the typology of state/change of state alternations. In Yearbook of morphology 2005, 83-117. Dordrecht: Springer.

Koontz-Garboden, Andrew. 2010. The lexical semantics of derived statives. Linguistics and Philosophy 33(4): 285-324.

Koontz-Garboden, Andrew, and John Beavers. 2017. Change of state verbs and the semantics of roots. In West Coast Conference on Formal Linguistics (WCCFL) 34, Summerville: Cascadilla Proceedings Project.

Koontz-Garboden, Andrew, and Beth Levin. 2005. The morphological typology of change of state event encoding. In Morphology and linguistic typology: On-line proceedings of the 4th Mediterranean morphology meeting, eds. Geert Booij, Emiliano Guevara, Angela Ralli, Salvatore Sgroi, and Sergio Scalise, 185-194. Bologna: Università degli Studi di Bologna.

Kratzer, Angelika. 1996. Severing the external argument from its verb. In Phrase structure and the lexicon, eds. Johan Rooryck and Laurie Zaring, 109-137. Dordrecht: Kluwer.

Kratzer, Angelika. 2000. Building statives. In Annual meeting of the Berkeley Linguistics Society (BLS) 26 (Vol. 1, 385-399).

Kratzer, Angelika. 2004. Telicity and the meaning of objective case. In The syntax of time, eds. Jacqueline Guéron and Jacqueline Lecarme, 389-423. Cambridge: Cambridge University Press.

Kratzer, Angelika. 2005. Building resultatives. In Event arguments: Foundations and applications, eds. Claudia Maienborn, and Angelika Wöllstein, 177-212. Tübingen: de Gruyter.

Kratzer, Angelika. 2015. Creating a family: transfer of possession. In Handout of a talk at the Workshop modality across categories, 5-6. Barcelona: Universitat Pompeu Fabra. November.

Krifka, Manfred. 1989. Nominal reference, temporal constitution and quantification in event semantics. In Semantics and contextual expressions, eds. Renate Bartsch, Johan van Benthem, and Peter van Emde Boas, 75-115. Dordrecht: Foris Publications.

Kripke, Saul A. 1990/2009. Presupposition and anaphora: Remarks on the formulation of the projection problem. Linguistic Inquiry 40:367-386. Edited transcript of paper presented at Linguistic and Philosophical Approaches to the Study of Anaphora, Princeton University, October 1990.

Landman, Fred, and Susan Rothstein. 2010. Incremental homogeneity in the semantics of aspectual forphrases. In Syntax, lexical semantics and event structure, eds. Malka Rappaport Hovav, Ivy Sichel, and Edit Doron. Amsterdam: Benjamins.

Larson, Richard K. 1988. On the double object construction. Linguistic inquiry 19(3): 335-391.

Larson, Richard K. 1990. Double objects revisited: Reply to Jackendoff. Linguistic inquiry 21(4): 589632.

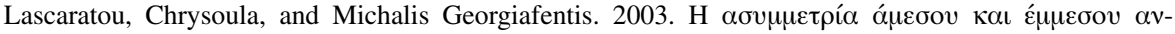

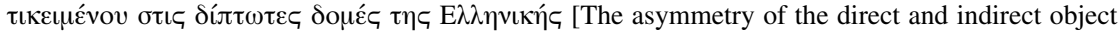
in Greek ditransitive structures]. In 6th international conference on Greek linguistics, eds. Georgia Katsimali, Alexis Kalokairinos, Elena Anagnostopoulou, and Ioanna Kappa. Rethymno: University of Crete.

Lechner, Winfried, Giorgos Spathas, Artemis Alexiadou, and Elena Anagnostopoulou. 2015. On deriving the typology of repetition and restitution. Talk given at GLOW.

Levin, Beth. 2000. Aspect, lexical semantic representation, and argument expression. In Proceedings of the 26th Annual Meeting of the Berkeley Linguistics Society, eds. Lisa J. Conathan, Jeff Good, Darya Kavitskaya, Alyssa B. Woolf, and Alan C. L. Yu, 413-429. Berkeley: Berkeley Linguistics Society.

Levin, Beth, and Malka Rappaport Hovav. 2014. Manner and result. In Language description informed by theory $147,337$.

Lohndal, Terje. 2014. Phrase structure and argument structure: A case study of the syntax-semantics interface. Oxford: Oxford University Press.

Maienborn, Claudia. 2005. On the limits of the Davidsonian approach: The case of copula sentences. Theoretical Linguistics 31(3): 275-316.

Marantz, Alec. 1992. The way construction and the semantics of direct arguments in English. In Syntax and the lexicon, 179-188. Leiden: Brill Academic Press.

Marantz, Alec. 1993. Implications of asymmetries in double object constructions. Theoretical aspects of Bantu grammar, 113-150. Stanford: CSLI.

Marantz, Alec. 2009a. Resultatives and re-resultatives: Direct objects may construct events by themselves. Paper presented at the University of Pennsylvania Linguistics Speaker Series, Philadelphia, February 2009.

Marantz, Alec. 2009b. Roots, re-, and affected agents: Can roots pull the agent under little v? In Talk given at Roots workshop. Stuttgart, Germany: Universität Stuttgart. June 10-13. 
Martin, Fabienne, and Florian Schäfer. 2014. Causation at the syntax-semantics interface. In Causation in grammatical structures, eds. Bridget Copley and Fabienne Martin. London: Oxford University Press.

McCready, Elin. 2003a. Discourse anaphora, verbs of creation, and the progressive. Qualifying paper, Department of Linguistics. University of Texas at Austin.

McCready, Elin. 2003b. Anaphora and (un) finished objects. In West Coast Conference on Formal Linguistics (WCCFL) 23.

McNally, Louise. 2017. Scalar alternatives and scalar inference involving adjectives: A comment on van Tiel, et al. 2016. In Asking the right questions: Essays in honor of Sandra Chung, eds. Jason Ostrove, Ruth Kramer, and Joseph Sabbagh Leds, 17-28. Retrieved from https://escholarship.org/uc/item/8255v8sc.

Michelioudakis, Dimitis. 2012. Dative arguments and abstract case in Greek. PhD diss., Department of Theoretical and Applied Linguistics, University of Cambridge.

Neeleman, Ad. 1994. Complex Predicates. Ph.D. Diss., Utrecht University/OTS.

Neeleman, Ad, and Hans Van de Koot. 2002. Bare resultatives. The Journal of Comparative Germanic Linguistics 6(1): 1-52.

Neeleman, Ad, and Hans Van de Koot. 2017. The non-existence of sub-lexical scope. In Linguistic variations: Structure and interpretation. A festschrift in honour of Rita Manzini, eds. Ludovico Franco and Paolo Lorusso. Berlin: Mouton de Gruyter.

Oehrle, Richard Thomas. 1976. The grammatical status of the English dative alternation. PhD diss., MIT.

Ormazabal, Javier, and Juan Romero. 2010. The derivation of dative alternations. In Argument structure and syntactic relations: A cross-linguistic perspective, eds. Maia Duguine, Susana Huidobro, and Nerea Madariaga, 203-232. Amsterdam: Benjamins.

Parsons, Terence. 1990. Events in the semantics of English. Cambridge: MIT Press.

Pedersen, Walter A. 2014. A scalar analysis of again-ambiguities. Journal of Semantics 32(3): 1-52.

Pesetsky, David. M. 1996. Zero syntax: Experiencers and cascades (No. 27). Cambridge: MIT Press.

Pietroski, Paul M. 2005. Events and semantic architecture. Oxford: Oxford University Press.

Piñón, Christopher. 1999. Durative adverbials for result states. In West Coast Conference on Formal Linguistics (WCCFL) 18, 420-433. Somerville: Casadilla Press.

Piñón, Christopher. 2006. Modal adverbs again. Presented at Workshop on syntax, lexicon and event structure. The Hebrew University of Jerusalem.

Piñón, Christopher. 2008. Aspectual composition with degrees. In Adjectives and adverbs: Syntax, semantics and discourse, eds. Louise McNally and Christopher Kennedy, 183-219. New York: Oxford University Press.

Pross, Tillmann. 2019. What about lexical semantics if syntax is the only generative component of the grammar? Natural Language \& Linguistic Theory 37(1): 215-261.

Pross, Tillmann, and Antje Roßdeutscher. 2019. Towards a correlation of form, use and meaning of German ge-prefixed predicative participles. Glossa: A Journal of General Linguistics 4(1): 93.

Pustejovsky, James. 1991. The syntax of event structure. Cognition 41: 47-81.

Pylkkänen, Liina. 2002/2008. Introducing arguments, Vol. 49. Cambridge: MIT Press.

Ramchand, Gillian. 2008. Verb meaning and the lexicon: a first-phase syntax. Cambridge: Cambridge University Press.

Rapp, Irene, and Arnim von Stechow. 1999. Fast 'almost' and the visibility parameter for functional adverbs. Journal of Semantics 16: 149-204.

Rappaport Hovav, Malka. 2008. Lexicalized meaning and the internal temporal structure of events. In Theoretical and crosslinguistic approaches to the semantics of aspect, ed. Susan Rothstein. Amsterdam, Netherlands: Benjamins.

Rappaport Hovav, Malka. 2014. Building scalar changes. In The syntax of roots and the roots of syntax, eds. Artemis Alexiadou, Hagit Borer, and Florian Schäfer, 259-281. Oxford: Oxford University Press.

Rappaport Hovav, Malka. 2018. Modern Hebrew in transit: the shift from a V-framed to an S-framed profile. Paper presented at IATL 34, October 8-9 2018, Ben Gurion University.

Rappaport Hovav, Malka, and Beth Levin. 1998. Building verb meanings. In The projection of arguments: Lexical and compositional factors, eds. Miriam Butt and Wilhelm Geuder, 97-133. Stanford: CSLI Publications.

Rappaport Hovav, Malka, and Beth Levin. 2010. Reflections on manner/result complementarity. In Syntax, lexical semantics, and event structure, eds. Edit Doron, Malka Rappaport Hovav, and Ivy Sichel, 2338. Oxford: Oxford University Press.

Rooth, Mats. 1985. Association with focus. PhD diss., University of Massachusetts, Amherst. Rooth, Mats. 1992. A theory of Focus interpretation. Natural Language Semantics 1: 75-116. 
Roßdeutscher, Antje, and Hans Kamp. 2010. Syntactic and semantic constraints in the formation and interpretation of ung-nouns. In The semantics of nominalisations across languages and frameworks, eds. Monika Rathert and Artemis Alexiadou, 169-214. Berlin: Mouton de Gruyter.

Rothstein, Susan. 2004. Structuring events: a study in the semantics of lexical aspect. Oxford: Blackwell.

Schäfer, Florian. 2008. The syntax of (anti-)causatives: External arguments in change-of-state contexts. Amsterdam/Philadelphia: John Benjamins.

Spathas, Giorgos. 2019. An ambiguity account of degree achievement predicates: evidence from additive operators. In North East Linguistic Society (NELS) 49, eds. Maggie Baird and Jonathan Pesetsky. Vol. 3, 163-172. Summerville: Cascadilla Press.

Talmy, Leonard. 1985. Lexicalization patterns: Semantic structure in lexical forms. In Language typology and syntactic description, vol. III: Grammatical categories and the lexicon, ed. Timothy Shopen, 57-149. Cambridge: Cambridge University Press.

Terzi, Arhonto. 2010a. Locative prepositions and place. Mapping spatial PPs. In The cartography of syntactic structures 6, eds. Guglielmo Cinque, and Luigi Rizzi, 196-224. Oxford: Oxford University Press.

Terzi, Arhonto. 2010b. On null spatial ps and their arguments. Catalan Journal of Linguistics 9: 167-187.

Tsiplakou, Stavroula. 2005. The Greek connective ke: Towards a unitary radical pragmatic account. In Annual Penn Linguistics Colloquium (PLC) 28, 293-304. Philadelphia: University of Pennsylvania.

von Stechow, Arnim. 1996. The different readings of wieder 'again': A structural account. Journal of Semantics 13: 87-138.

von Stechow, Arnim. 2000. How are results represented and modified? Remark's on Jäger and Blutner's anti-decomposition. ZAS Papers in Linguistics 17: 287-308.

von Stechow, Arnim. 2001a. How are results represented and modified? Remark's on Jäger and Blutner's anti-decomposition. Ms., University of Tübingen.

von Stechow, Arnim. 2001b. Temporally opaque arguments in verbs of creation. In Semantic interfaces, eds. Carlo Cecchetto, Gennaro Chierchia, and Maria Teresa Guasti, 278-319. Stanford: CSLI Publications.

von Stechow, Arnim. 2004. On the perfect of result, German predicative participles and Japanese $t e-i r-u$. Ms., University of Tübingen.

von Stechow, Arnim. 2007. Syntactic and lexical causativization: BECOME and CAUSE again. Presentation at ConSOLE 15, Brussels.

Wagner, Michael. Association by Movement. Evidence from NPI-Licensing. Natural Language Semantics 14: 297-324.

Wechsler, Stephen. 2005. Resultatives under the 'event-argument homomorphism' model of telicity. In The syntax of aspect, eds. Nomi Erteschk-Shir and Tova Rapoport, 255-273. Oxford: Oxford University Press.

Williams, Alexander. 2005. Complex causatives and verbal valence. PhD diss., University of Pennsylvania.

Williams, Alexander. 2015. Arguments in syntax and semantics. Cambridge: Cambridge University Press.

Winter, Yoad. 2006. Closure and telicity across categories. In Semantics and Linguistic Theory (SALT) 16, eds. Christopher Tancredi, Makoto Kanazawa, Ikumi Imani, and Kiyomi Kusumoto. Ithaca: Cornell University.

Wood, Jim, and Alec Marantz. 2015. The interpretation of external arguments. In The verbal domain, eds. Roberta D’Alessandro, Irene Franco, and Angel J. Gallego, 255-278. Oxford: Oxford University Press.

Zwarts, Joost. 2005. Prepositional aspect and the algebra of paths. Linguistics and Philosophy 28(6): 739779.

Zwarts, Joost. 2006. Event shape: Paths in the semantics of verbs. Ms., Radboud University Nijmegen.

Zwarts, Joost. 2019. From "back" to "again" in Dutch: The structure of the "re" domain. Journal of Semantics 36(2): 211-240.

Zwarts, Joost, and Yoad Winter. 2000. Vector space semantics: A model theoretic analysis of locative prepositions. Journal of Logic, Language and Information 9(2): 169-211. 